\title{
Exploring the possibility of using fluorine-involved non-conjugated electron-withdrawing groups for thermally activated delayed fluorescence emitters by TD-DFT calculation
}

\author{
Dongyang Chen and Eli Zysman-Colman ${ }^{\star} \S$
}

\author{
Full Research Paper \\ Address: \\ Organic Semiconductor Centre, EaStCHEM School of Chemistry, \\ University of St Andrews, St Andrews, Fife, KY16 9ST, UK \\ Email: \\ Eli Zysman-Colman ${ }^{*}$ - eli.zysman-colman@st-andrews.ac.uk \\ * Corresponding author \\ § Fax: +44-1334 463808; Tel: +44-1334 463826 \\ Keywords: \\ DFT calculation; pentafluorosulfanyl; spin-orbit coupling; TADF; \\ trifluoromethoxy; trifluoromethylthio
}

\author{
Beilstein J. Org. Chem. 2021, 17, 210-223. \\ https://doi.org/10.3762/bjoc.17.21 \\ Received: 11 November 2020 \\ Accepted: 05 January 2021 \\ Published: 21 January 2021 \\ This article is part of the thematic issue "Organo-fluorine chemistry V". \\ Guest Editor: D. O'Hagan \\ (C) 2021 Chen and Zysman-Colman; licensee Beilstein-Institut. \\ License and terms: see end of document.
}

\begin{abstract}
The trifluoromethyl group has been previously explored as a non-conjugated electron-withdrawing group in donor-acceptor thermally activated delayed fluorescence (TADF) emitters. In the present study, we investigate computationally the potential of other fluorine-containing acceptors, trifluoromethoxy $\left(\mathrm{OCF}_{3}\right)$, trifluoromethylthio $\left(\mathrm{SCF}_{3}\right)$, and pentafluorosulfanyl $\left(\mathrm{SF}_{5}\right)$, within two families of donor-acceptor TADF emitters. Time-dependent density functional theory calculations indicate that when only two ortho-disposed carbazole donors are used (Type I molecules), the lowest-lying triplet state possesses locally excited (LE) character while the lowest-lying singlet state possesses charge-transfer character. When five carbazole donors are present in the emitter design (Type II molecules), now both $\mathrm{S}_{1}$ and $\mathrm{T}_{1}$ states possess $\mathrm{CT}$ character. For molecules $\mathbf{2} \mathbf{C z O C F}_{\mathbf{3}}$ and $\mathbf{5 C z O C F}_{\mathbf{3}}$, the singlet energies are predicted to be $3.92 \mathrm{eV}$ and $3.45 \mathrm{eV}$; however, the singlet-triplet energy gaps, $\Delta E_{\mathrm{ST}} \mathrm{s}$, are predicted to be large at $0.46 \mathrm{eV}$ and $0.37 \mathrm{eV}$, respectively. The compounds $\mathbf{2} \mathbf{C z C F}_{\mathbf{3}}, \mathbf{2} \mathbf{C z S C F}_{\mathbf{3}}$, and $\mathbf{2} \mathbf{C z S F}_{\mathbf{5}}$, from Type I molecules, show significant promise as deep blue TADF emitters, possessing high calculated singlet energies in the gas phase $(3.62 \mathrm{eV}, 3.66 \mathrm{eV}$, and $3.51 \mathrm{eV}$, respectively) and small, $\Delta E_{\mathrm{ST}} \mathrm{s}$, of $0.17 \mathrm{eV}, 0.22 \mathrm{eV}$, and $0.07 \mathrm{eV}$, respectively. For compounds $\mathbf{5} \mathbf{C z S C F}_{\mathbf{3}}$ and $\mathbf{5} \mathbf{C z S F}_{\mathbf{5}}$, from Type II molecules, the singlet energies are stabilized to $3.24 \mathrm{eV}$ and $3.00 \mathrm{eV}$, respectively, while $\Delta E_{\mathrm{ST}} \mathrm{S}$ are $0.27 \mathrm{eV}$ and $0.12 \mathrm{eV}$, respectively, thus both show promise as blue or sky-blue TADF emitters. All these six molecules possess a dense number of intermediate excited states between $S_{1}$ and $T_{1}$, thus likely leading to a very efficient reverse intersystem crossing in these compounds.
\end{abstract}




\section{Introduction}

Organic thermally activated delayed fluorescence (TADF) materials have generated significant attention recently, particularly for their use as emitters in organic light-emitting diodes (OLEDs). This is due to their ability to utilize both singlet excitons and triplet excitons, thereby increasing the theoretical internal quantum efficiency (IQE) to $100 \%$ from $25 \%$ for fluorescent compounds [1-4]. For TADF materials, a small energy gap between the lowest singlet and triplet excited states $\left(\Delta E_{\mathrm{ST}}\right)$ is essential to permit the efficient up-conversion of triplet excitons to singlet excitons via reverse intersystem crossing (rISC) [5-7]. The rISC process can happen by hyperfine coupling when the $\Delta E_{\mathrm{ST}}$ is sufficiently small $(<10 \mathrm{meV})$ or spin orbit coupling (SOC), which requires different symmetry between the two states coupled with a relatively small singlet-triplet energy gap, $\Delta E_{\mathrm{ST}},(<300 \mathrm{meV})[8,9]$. The $\Delta E_{\mathrm{ST}}$ is directly dependent on the magnitude of the electron exchange energy $J$ (Equation 1), which itself is dependent on the electron density overlap between the highest occupied molecular orbital (HOMO) and lowest unoccupied molecular orbital (LUMO) (Equation 2) $[10,11]$. Compounds possessing a donor-acceptor (D-A) structure could satisfy the requirements for efficient TADF if the donor and acceptor moieties are poorly conjugated with each other in order to minimize $J$. The HOMO/LUMO separation that controls $J$ can be modulated by introducing strong and bulky electron donors and electron acceptors to produce large torsions between the donor and acceptor groups so as to localized the HOMO on the electron-donating moiety and to confine the LUMO on the electron-withdrawing moiety $[12,13]$.

$$
\begin{array}{r}
\Delta E_{\mathrm{ST}}=E_{\mathrm{orb}}^{\mathrm{S}}+K+J-\left(E_{\mathrm{orb}}^{\mathrm{T}}+K-J\right)=2 J+\left(E_{\mathrm{orb}}^{\mathrm{S}}-E_{\mathrm{orb}}^{\mathrm{T}}\right) \\
J=\iint \Phi_{\mathrm{LUMO}}\left(r_{2}\right) \Phi_{\mathrm{HOMO}}\left(r_{1}\right)\left(\frac{e^{2}}{\left(r_{1}-r_{2}\right)}\right) \\
\Phi_{\mathrm{LUMO}}\left(r_{1}\right) \Phi_{\mathrm{HOMO}}\left(r_{2}\right) \mathrm{dr}_{1} \mathrm{dr}_{2}
\end{array}
$$

According to the Fermi's golden rule, the reversed intersystem crossing rate $\left(k_{\mathrm{rISC}}\right)$ can be expressed as $[14,15]$ :

$$
k_{\mathrm{rISC}}=\frac{2 \pi}{\hbar} 2\left|V_{\mathrm{SOC}}\right|^{2} \times \rho_{F C W D}
$$

Where $\left|V_{\text {SOC }}\right|^{2}$ is the spin-orbit coupling matrix element between $S_{1}$ and $T_{1}$ and $\rho_{\text {FCWD }}$ is the Franck-Condon-weighted density of states, which can be expressed as [16]:

$$
\rho_{F C W D}=\frac{1}{\sqrt{4 \pi \lambda k_{\mathrm{B}} T}} \exp \left(-\frac{\left(\Delta E_{\mathrm{ST}}+\lambda\right)^{2}}{4 \lambda k_{\mathrm{B}} T}\right)
$$

where $\lambda$ is the Marcus reorganization energy associated with the intermolecular and intramolecular low-frequency vibrations; $k_{\mathrm{B}}$ is Boltzmann's constant; and $T$ is temperature. Combing Equation 3 and Equation 4 , it is evident that $k_{\mathrm{rISC}}$ is proportional to $\left|V_{\mathrm{SOC}}\right|^{2} \times \exp \left[-\left(\Delta E_{\mathrm{ST}}{ }^{2}\right)\right]$. Further, judicious molecular design in terms of the identity, position, and number of donor to acceptor moieties can also contribute to the modulation of $\Delta E_{\mathrm{ST}}$, leading to faster rISC. Typical donors include a small group of structurally related $N$-heterocycles such as carbazole [5], dimethylacridine [13], phenoxazine [17], and phenothiazine [18].

Prior studies have shown that placing the donor groups ortho to the acceptor can lead to more limited conjugation between the two, resulting in emitters with relatively smaller $\Delta E_{\mathrm{ST}}$ compared to analogous compounds where the donor is positioned para to the acceptor $[19,20]$. Duan et al. have investigated the properties of D-A TADF benzonitrile-based emitters containing two carbazole donors disposed at different positions about the phenylene bridge [19]. The results showed that when the carbazoles were both located ortho to the cyano acceptor the molecule (2,6-2CzBN) possessed a highly twisted structure and a corresponding small $\Delta E_{\mathrm{ST}}\left(0.27 \mathrm{eV}\right.$ in toluene). The $\Delta E_{\mathrm{ST}} \mathrm{s}$ increased to $0.41(\mathbf{2}, \mathbf{4 - 2 C z B N})$ and $0.40 \mathrm{eV}(\mathbf{3 , 5 - 2 C z B N})$ in toluene when at least one of the carbazoles was disposed meta or para to the cyano acceptor [19]. OLEDs fabricated using 2,62CzBN as the emitter exhibited deep blue emission with $\lambda_{\mathrm{EL}}=418 \mathrm{~nm}$ and CIE coordinate of $(0.15,0.05)$; however, due to the low photoluminescence quantum yields $\left(\Phi_{\mathrm{PL}^{\mathrm{S}}} \mathrm{s}\right)(28 \%$ in $10 \mathrm{wt} \%$ DPEPO films) and relatively slow $k_{\text {rISC }}$ $\left(0.86 \times 10^{5} \mathrm{~s}^{-1}\right)$ in the DPEPO host, the EQE $\max$ was only $2.5 \%$, and showed significant efficiency roll-off, reducing to $0.1 \%$ at $50 \mathrm{~cd} \cdot \mathrm{m}^{-2}$ [21]. A similar study by Monkman, Lee and co-workers investigated the compound 2,6-2CzTRZ, which possessed the smallest $\Delta E_{\mathrm{ST}}(0.02 \mathrm{eV})$ amongst the family of emitters possessing a diphenyltriazine as the acceptor and different regiochemistry of the carbazole donors; the $\Delta E_{\mathrm{ST}} \mathrm{s}$ increased to $0.10 \mathrm{eV}$ for $\mathbf{2 , 4 - 2 C z T R Z}$ and $0.29 \mathrm{eV}$ for $\mathbf{3 , 4}$ 2CzTRZ. The single crystal structure of 2,6-2CzTRZ revealed a highly twisted structure with large torsions $\left(81.0^{\circ}\right.$ and $\left.76.3^{\circ}\right)$ between the carbazole moieties and the central benzene ring; the same torsions are appreciably smaller at $45.6^{\circ}$ and $69.6^{\circ}$ for the molecule 2,4-2CzTRZ where one of the carbazole donors is situated at the para position and another one situated at the ortho position [20]. Compound 2,6-2CzTRZ possessed a very small $\Delta E_{\mathrm{ST}}(0.02 \mathrm{eV})$ and short delayed fluorescence lifetime $\left(\tau_{\mathrm{d}}=16.4 \mu \mathrm{s}\right)$ in zeonex [20]. These two studies illustrate that ortho-substituted D-A molecules possess highly twisted geometries, leading to spatially separated HOMO/LUMO distributions and, thus, small $\Delta E_{\mathrm{ST}} \mathrm{s}$, while maintaining high energy excited states 
The presence of intermediate triplet states lying above $\mathrm{T}_{1}$ and below $\mathrm{S}_{1}$ have been shown to facilitate rISC and render TADF more efficient by opening up a reverse internal conversion (RIC) pathway that is mediated by spin-vibronic coupling between $T_{1}$ and one or more of the intermediate states, followed by rISC [22]. This situation typically occurs when there are multiple donors about a single acceptor as exists in the molecules 5CzBN and 5CzTRZ. For 5CzBN, time-dependent density functional theory (TD-DFT) calculation revealed the existence of three intermediate triplet states [22]. The presence of these states helped to explain the short $\tau_{\mathrm{d}}$ of $3.7 \mu \mathrm{s}$ and the high $\mathrm{EQE}_{\max }$ of $17 \%$ and good device stability with a $\mathrm{T}_{50}$ of 176 hours for the OLED [CIE coordinate $(0.22,0.40)$ ] [23]. In an analogous manner, TD-DFT calculations predicted 5CzTRZ to possess a small $\Delta E_{\mathrm{ST}}(0.02 \mathrm{eV})$ as well as a small energy gap $(\approx 0.24 \mathrm{eV})$ between $\mathrm{T}_{2}$ and $\mathrm{T}_{1}[24]$. In an analogous manner, 5CzTRZ showed very fast $\mathrm{k}_{\mathrm{rISC}}$ of $\approx 1.5 \times 10^{7} \mathrm{~s}^{-1}$ in toluene, and the device based on 5CzTRZ exhibited superior $\mathrm{EQE}_{\max }=29 \%$ with $\lambda_{\mathrm{EL}}=486 \mathrm{~nm}$ and very low efficiency rolloff with the EQE at $5,000 \mathrm{~cd} \cdot \mathrm{m}^{-2}$ remaining high at $27 \%$ [24].
Huang et al. also adopted a multiple donor strategy in concert with the weak trifluoromethyl $\left(\mathrm{CF}_{3}\right)$ acceptor group in their TADF emitter design. The blue-emitting TADF emitter $\mathbf{5 C z C F}_{\mathbf{3}}$ possessed a miniscule measured $\Delta E_{\mathrm{ST}}$ of $0.02 \mathrm{eV}$ and $\Phi_{\mathrm{PL}}$ of $43 \%$ in oxygen-free toluene [25]. The solutionprocessed device based on $\mathbf{5 C z C F}_{\mathbf{3}}$ exhibited sky-blue emission with CIE coordinates of $(0.21,0.33)$ and an $\mathrm{EQE}_{\max }$ of $5.2 \%$ at $1 \mathrm{~cd} \cdot \mathrm{m}^{-2}[25]$.

The promising performance of emitters possessing a $\mathrm{CF}_{3}$ acceptor group prompted us to investigate other fluorinated weakly-conjugated acceptor units in order to assess their potential within TADF emitter design (Figure 1) [25-27]. In the present study, we report on the impact of incorporating other fluorine-containing electron-withdrawing groups beyond trifluoromethyl $\left(\mathrm{CF}_{3}\right)$, including trifluoromethoxy $\left(\mathrm{OCF}_{3}\right)$, trifluoromethylthio $\left(\mathrm{SCF}_{3}\right)$, and pentafluorosulfanyl $\left(\mathrm{SF}_{5}\right)$ groups, and explore their potential computationally within TADF emitter design. We cross-compare their optoelectronic properties with analog materials using well-studied conjugated elec-

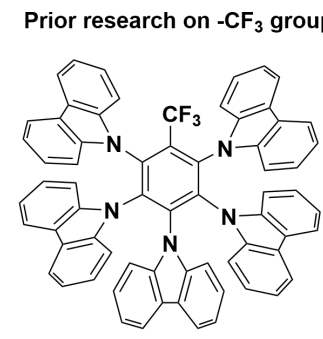

$5 \mathrm{CzCF}_{3}$

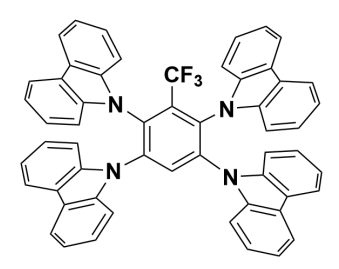

$4 \mathrm{CzCF}_{3}$

Reference [25]

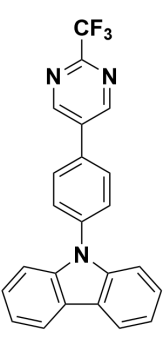

NTN-PCZ

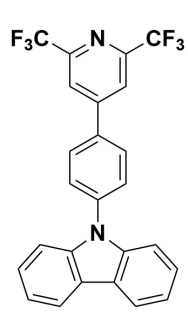

TN4T-PCZ

Reference [26]

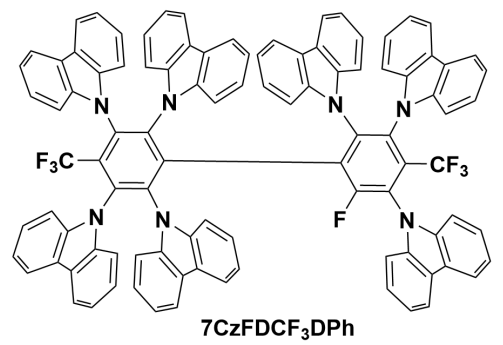

Reference [27]

Structures investigated in this work

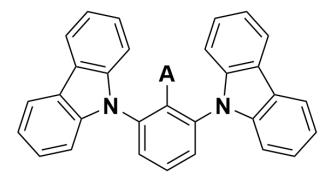

Type I

A: $-\mathrm{CF}_{3}$

A: $\quad-\mathrm{O}^{\prime} \mathrm{CF}_{3}$

A: $-s^{\prime} \mathrm{sF}_{3}$

A: $-\mathrm{SF}_{5}$

A: $=\mathrm{N}$
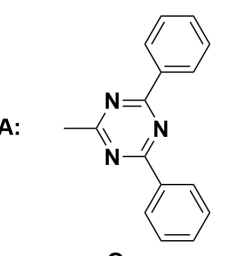

A:

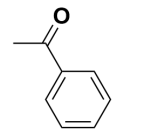

$2 \mathrm{CzSF}_{5}$

2CzBN

$2 \mathrm{CzCF}_{3}$

$2 \mathrm{CzOCF}_{3}$

$2 \mathrm{CzSCF}_{3}$

2CzTRZ

2CzBP

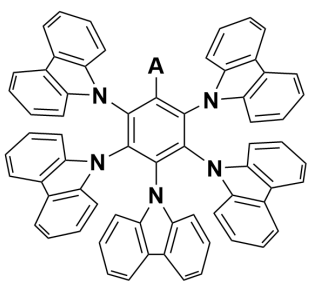

Type II

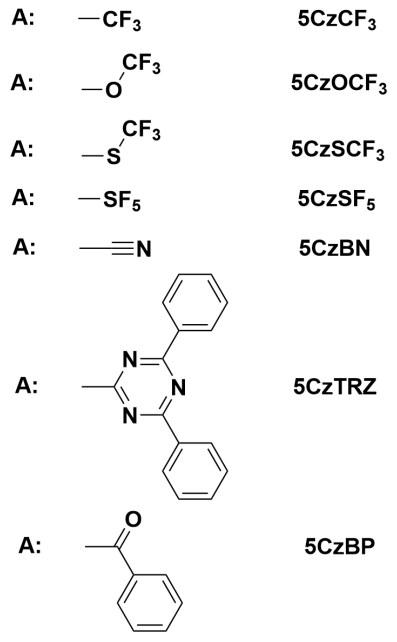

Figure 1: Molecular structures of emitters discussed in this work. 
tron-withdrawing groups (cyano, benzophenone, and triazine). We investigated two families of structures. The first family consists of D-A-D (Type I) molecules containing two carbazole donors disposed each ortho to the acceptor group, while the second family consists of five carbazole donors substituted about a central benzene ring and the sixth position occupied by the acceptor moiety (Type II). Adachi et al. have shown that compounds that fall within the Type I family can simultaneously show high singlet and triplet energies and small $\Delta E_{\mathrm{ST}}$ while compounds that are a part of Type II family possess a more dense number of low-lying excited states [22], the presence of which has been shown to assist in the rISC process through spin-vibronic coupling $[23,24,27]$. The energy levels and electronic configurations of $S_{1}$ and $T_{1}$ in these molecules were analysed and we found that compounds possessing either $\mathrm{SCF}_{3}$ and $\mathrm{SF}_{5}$ groups as acceptors $\left(\mathbf{2 C z S C F}_{\mathbf{3}} / \mathbf{2 C z S F}_{\mathbf{5}}\right.$ in Type I, $\mathbf{5 C z S C F}_{\mathbf{3}} / \mathbf{5 C z S F}_{\mathbf{5}}$ in Type II), possessed LUMOs that are mainly located on the central benzene ring and the acceptor group while the HOMOs are mainly localized on the carbazoles, thereby leading to small $\Delta E_{\mathrm{ST}} \mathrm{s}$. The calculated $\Delta E_{\mathrm{ST}} \mathrm{s}$ for $\mathbf{2 C z S C F}_{\mathbf{3}} / \mathbf{2 C z S F}_{\mathbf{5}}$ are $0.22 \mathrm{eV}$ and $0.07 \mathrm{eV}$, respectively, which are comparable to the calculated results for $\mathbf{2 C z B N}(0.18 \mathrm{eV})$ and $2 \mathrm{CzTRZ}(0.08 \mathrm{eV})$; likewise, the calculated $\Delta E_{\mathrm{ST}^{\mathrm{S}}}$ for $\mathbf{5 C z S C F}_{\mathbf{3}} / \mathbf{5 C z S F}_{\mathbf{5}}$ are $0.27 \mathrm{eV}$ and $0.12 \mathrm{eV}$, respectively, which are close to the calculated results of $5 \mathbf{C z B N}(0.20 \mathrm{eV})$ and 5CzTRZ $(0.17 \mathrm{eV})$. The molecules incorporating an $\mathrm{OCF}_{3}$ acceptor $\left(\mathbf{2} \mathbf{C z O C F}_{\mathbf{3}}\right.$ in Type I, $\mathbf{5 C z O C F}_{\mathbf{3}}$ in Type II), however, exhibited relatively larger $\Delta E_{\mathrm{ST}^{\mathrm{s}}}(0.46 \mathrm{eV}$ for $\mathbf{2} \mathbf{C z O C F}$, $0.37 \mathrm{eV}$ for $\mathbf{5 C z O C F}_{3}$ ). The calculated $\mathrm{S}_{1}$ energies of $\mathbf{2 C z O C F}_{\mathbf{3}}(3.92 \mathrm{eV}), \mathbf{2 C z S C F}_{\mathbf{3}}(3.62 \mathrm{eV}), \mathbf{2 C z S F}_{\mathbf{5}}(3.51 \mathrm{eV})$, and $\mathbf{5 C z O C F}_{\mathbf{3}}(3.45 \mathrm{eV})$ demonstrate that these molecules show potential as deep blue emitters as their $\mathrm{S}_{1}$ states are higher in energy than that of $\mathbf{2 C z B N}$ ( $3.34 \mathrm{eV}$ calculated in gas phase in this work), which was reported as deep blue emitter with $\lambda_{\mathrm{EL}}=418 \mathrm{~nm}$ and CIE coordinate of $(0.15,0.05)$ when doped in DPEPO [21]. DFT calculations for $\mathbf{5} \mathbf{C z O C F}_{\mathbf{3}}$, $\mathbf{5 C z S C F}_{\mathbf{3}}$, and $\mathbf{5 C z S F}_{\mathbf{5}}$ predicted dense populations of excited states between $T_{1}$ and $S_{1}$, which should assist in rISC process [28,29].

\section{Results and Discussion}

We employed density functional theory (DFT) and TD-DFT calculations to predict the photophysical properties of these emitters in order to assess their potential as TADF emitters for OLEDs. All ground-state calculations were performed using PBE0/6-31G(d,p) in the gas phase [30,31]. The lowest energy structures from these DFT calculations were used as input geometries for excited-state calculations using the Tamm-Dancoff approximation (TDA) to TD-DFT, which provide computed energies of the excited singlet and triplet states $[32,33]$. The nature of the lowest singlet and triplet states were ascertained by an analysis of the natural transition orbitals (NTO) obtained from the TDA-DFT calculations [34].

We first investigated the strength of the acceptor groups by modelling phenyl-substituted acceptors and compared their LUMO energies as well as the energies of the $S_{1}$ and $T_{1}$ states (Figure 2). Among the fluorinated electron-withdrawing groups in the study, $\mathbf{P h O C F}_{3}$ possesses the shallowest LUMO at $-0.22 \mathrm{eV}$ while $\mathbf{P h S F}_{\mathbf{5}}$ possess the deepest LUMO at $-0.90 \mathrm{eV}$, with $\mathbf{P h S C F}_{\mathbf{3}}(-0.78 \mathrm{eV})$ and $\mathbf{P h C F}_{\mathbf{3}}(-0.57 \mathrm{eV})$ possessing intermediate values. The LUMO energies of these four acceptors correlate linearly to the Hammett substituent constant, $\sigma_{\mathrm{p}}$, (Figure 2c) [35]. All of these fluorinated acceptors are much weaker than the more commonly investigated benzonitrile (BN, $-1.30 \mathrm{eV})$, triphenyltriazine (TRZ, $-1.72 \mathrm{eV}$ ) and benzophenone (BP, $-1.58 \mathrm{eV}$ ) acceptors. These results indicate that the use of the fluorinated acceptor groups in donor-acceptor TADF emitters should lead to a pronounced blue-shift in the emission, as reflected in the higher-energy singlet states of the model systems in Figure 2.

We next modelled the Type I emitters (Figure 3 and Figure 4). The DFT-calculated geometries indicate that the carbazoles adopt a significantly twisted conformation (dihedral angles $>$ $50^{\circ}$ ) in order to minimize their interaction with the acceptor group. Specifically, for $\mathbf{2 C z C}_{\mathbf{3}}$ the carbazoles are twisted to $60.2^{\circ}$ and $70.5^{\circ}$ with respect to the bridging phenyl ring while for $\mathbf{2 Z S F}_{5}$, due to the increased bulkiness of the $\mathrm{SF}_{5}$ group, the corresponding twist angle increased to $78.5^{\circ}$ and $78.7^{\circ}$. These highly twisted conformations contribute to the spatial separation of the HOMO and LUMO.

Figure 3 shows the energies of the HOMOs and LUMOs and the $\mathrm{S}_{1}$ and $\mathrm{T}_{1}$ states for the fluorinated acceptor-containing

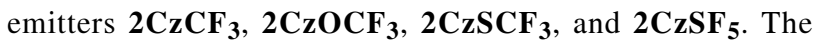
HOMOs in these compounds are mainly located on the two carbazole moieties and a small part on the bridging central benzene ring. The LUMOs of $\mathbf{2 C z C F}_{3}, \mathbf{2 C z S C F}_{3}$, and $2 \mathrm{CzSF}_{5}$ are mainly located on the benzene ring and a small distribution onto the electron-withdrawing group, whereas the LUMO of $\mathbf{2 C z O C F}_{3}$ is localized essentially only on the central benzene. Emitters $\mathbf{2 C z C F}_{3}, \mathbf{2 C z O C F}_{3}$, and $\mathbf{2 C z S C F}_{3}$ show similarly deep HOMO values at around $-5.80 \mathrm{eV}$, while the HOMO level of $\mathbf{2 C z S F}_{5}$ is more stabilized at $-5.89 \mathrm{eV}$. The trend in LUMO energies matches that observed for the model acceptors (Figure 2) where $\mathbf{2 C z O C F}_{3}$ possesses the shallowest LUMO of $-0.95 \mathrm{eV}$ while $\mathbf{2 C z S F}_{5}$ possesses the deepest LUMO level of $-1.46 \mathrm{eV} . \mathbf{2 C z O C F}_{\mathbf{3}}$ possesses the largest energy gap $\left(\Delta E_{\mathrm{g}}\right)$ at $4.83 \mathrm{eV}$ while the $\Delta E_{\mathrm{g}}$ for $\mathbf{2 C z S F}_{\mathbf{5}}$ is the smallest at $4.43 \mathrm{eV}$ amongst these four compounds. Figure 4 shows the correspond- 

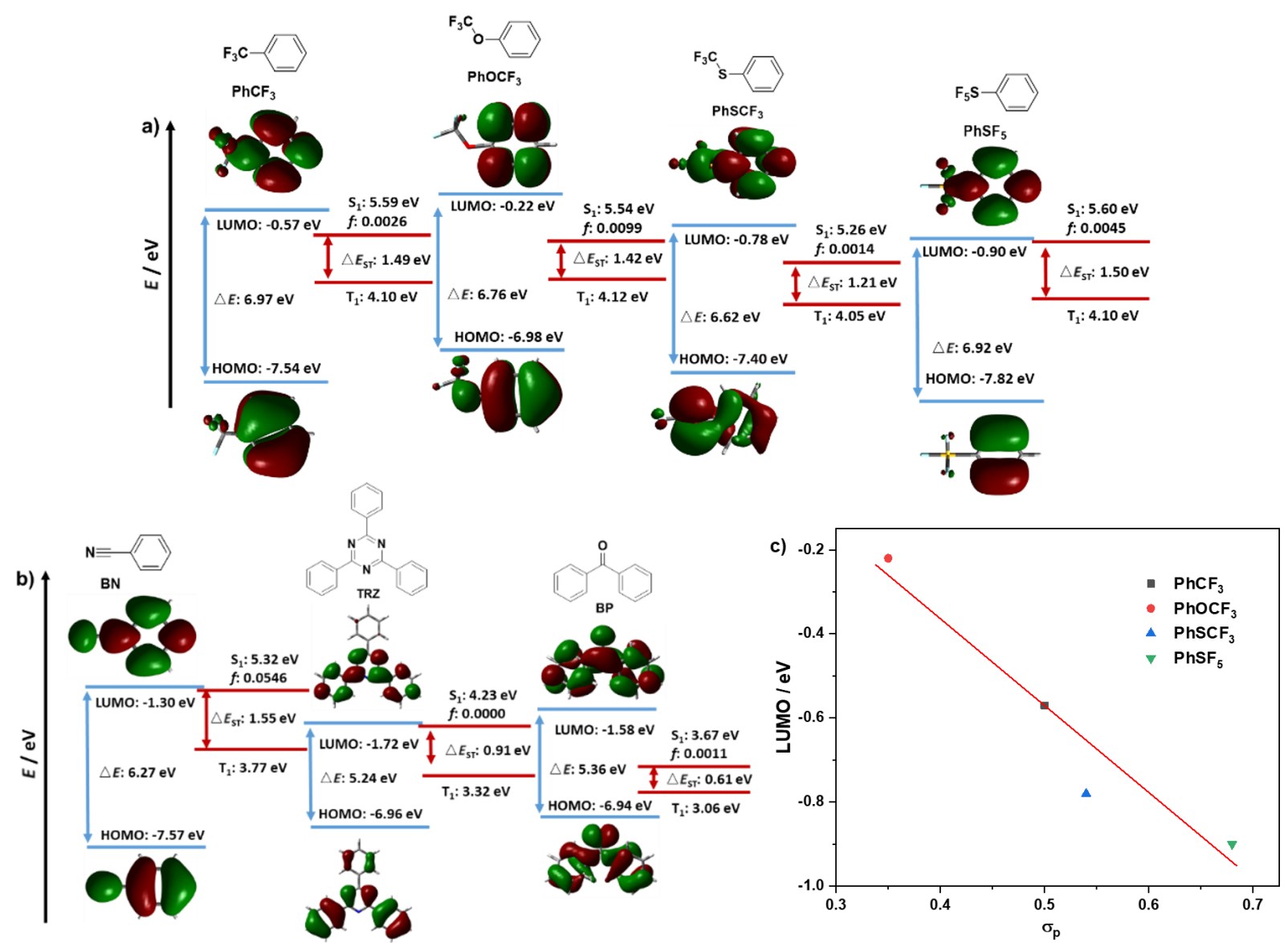

Figure 2: a) Calculated HOMO, LUMO, $\mathrm{S}_{1}$ and $\mathrm{T}_{1}$ energies, as well as $\mathrm{HOMO}$ and $\mathrm{LUMO}$ topologies of $\mathrm{PhCF}_{3}, \mathrm{PhOCF}_{3}, \mathrm{PhOSCF}_{3}$, and $\mathbf{P h S F}_{5}$, b) Calculated HOMO, LUMO, $S_{1}$ and $T_{1}$ energies, as well as HOMO and LUMO topologies of BN, TRZ and BP (isovalue $=0.02$ ). c) Hammett para substituent values $\left(\sigma_{\mathrm{p}}\right)$ relationship with the calculated $\mathrm{LUMO}$ energies for fluorine-containing acceptors $\mathrm{PhCF}_{3}, \mathrm{PhOCF}_{3}, \mathrm{PhOSCF}_{3}$, and $\mathbf{P h S F}_{5}$.

ing data for the Type I reference compounds $2 \mathrm{CzBN}$, 2CzTRZ, and 2CzBP. In these three compounds the HOMOs are located mostly on the two carbazole moieties, with only a small contribution from the bridging benzene ring; this latter contribution is most pronounced for $\mathbf{2 C z B N}$, which leads to the greatest stabilization of the HOMO level at $-5.89 \mathrm{eV}$. 2CzTRZ, and 2CzBP possess destabilized HOMO levels of -5.69 and $-5.60 \mathrm{eV}$, respectively. The LUMOs of $2 \mathrm{CzBN}, 2 \mathrm{CzTRZ}$ and $2 \mathrm{CzBP}$ are each located on the bridging benzene ring and the electronacceptor groups. The LUMO levels for 2CzBN, 2CzTRZ, and 2CzBP of $-1.70 \mathrm{eV},-1.63 \mathrm{eV}$, and $-1.67 \mathrm{eV}$, respectively, are much deeper those of the fluorine-containing emitters in Figure 3, which is a reflection of the greater conjugation length present in compounds with an extended $\pi$-accepting framework. The corresponding $\Delta E_{\mathrm{g}}$ of $\mathbf{2 C z B N}(4.19 \mathrm{eV}), \mathbf{2 C z T R Z}$ $(4.06 \mathrm{eV})$, and $\mathbf{2 C z B P}(3.93 \mathrm{eV})$ are all significantly smaller compared to those of $\mathbf{2 C z C F}_{3}, \mathbf{2 C z O C F}_{3}, \mathbf{2 C z S C F}_{3}$, and $\mathbf{2 z S F}_{5}$.
The emissive $\mathrm{S}_{1}$ state for the seven Type I molecules is characterized mainly by a HOMO to LUMO transition, while the distribution of highest occupied natural transition orbitals (HONTOs) and the lowest unoccupied natural transition orbitals (LUNTOs) show good agreement with the HOMOs and LUMOs (Figure 5 and Figure 6). As the HOMOs and LUMOs of the seven molecules are sufficiently separated, the nature of the $S_{1}$ is charge-transfer (CT) in character. The $S_{1}$ energies of

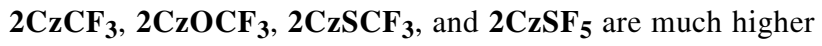
than those of $2 \mathrm{CzBN}, \mathbf{2 C z T R Z}$, and $2 \mathrm{CzBP}$. $\mathbf{2 C z O C F}_{3}$ possesses the highest $\mathrm{S}_{1}$ at $3.92 \mathrm{eV}$ followed by $\mathbf{2 C z S C F}_{3}$ $\left(3.66 \mathrm{eV}\right.$ ) and $\mathbf{2 C z C F}_{\mathbf{3}}(3.62 \mathrm{eV})$. The $\mathrm{S}_{1}$ of $\mathbf{2 C z S F}_{\mathbf{5}}$ at $3.51 \mathrm{eV}$ is relatively more stabilized due to the stronger electron-withdrawing ability of the $\mathrm{SF}_{5}$ group. The $\mathrm{S}_{1}$ states of $2 \mathbf{C z B N}$, 2CzTRZ, and 2CzBP are $3.34 \mathrm{eV}, 3.22 \mathrm{eV}$, and $3.09 \mathrm{eV}$, respectively. The calculated $S_{1}$ values are slightly destabilized relative to the literature reported values for $\mathbf{2 C B B N}(3.27 \mathrm{eV}$ in toluene [19]) and 2CzTRZ (3.12 eV in zeonex [20]). 

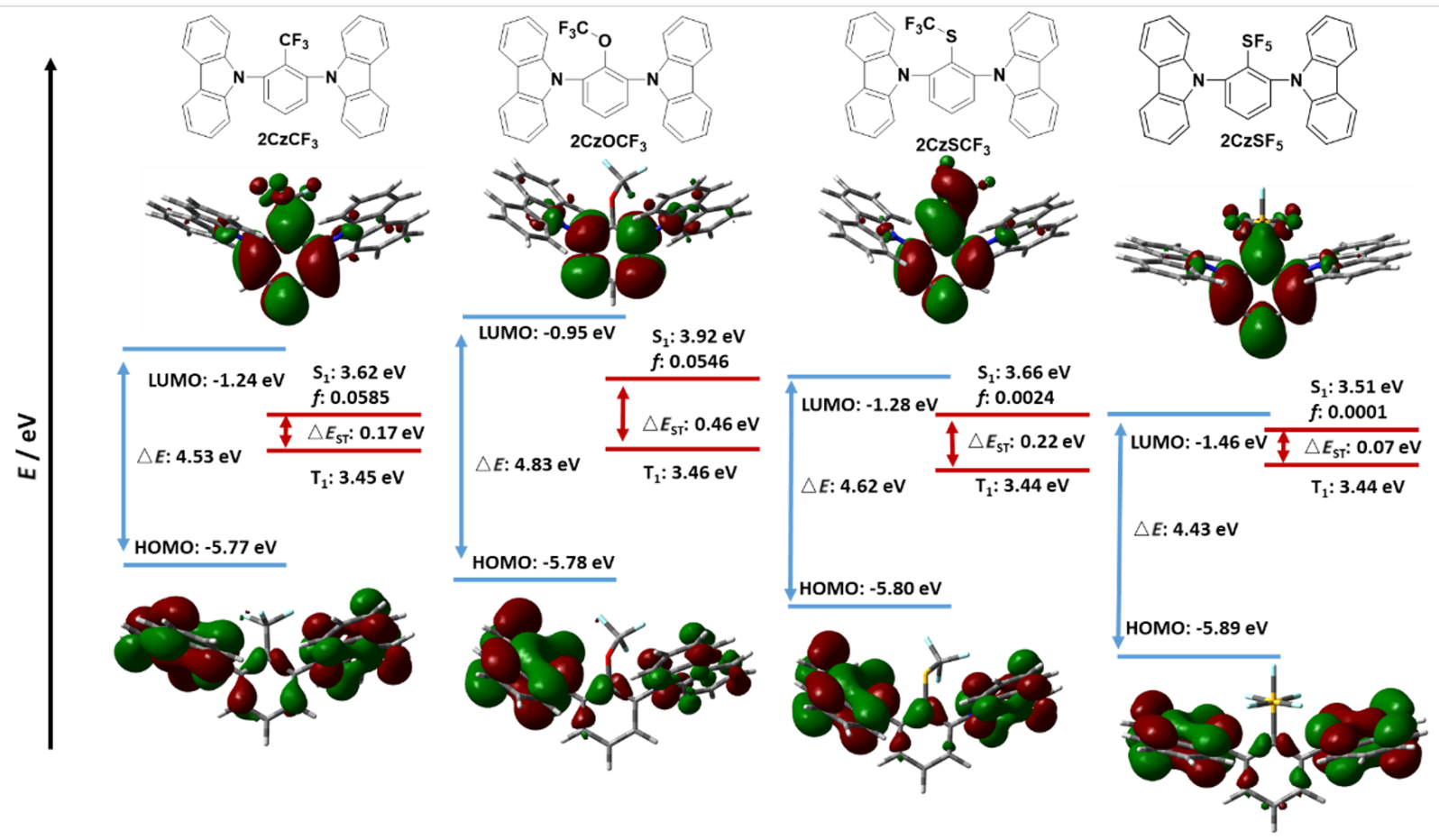

Figure 3: Calculated HOMO, LUMO, $\mathrm{S}_{1}$ and $\mathrm{T}_{1}$ energies, as well as $\mathrm{HOMO}$ and $\mathrm{LUMO}$ topologies of $2 \mathrm{CzCF}_{3}, \mathbf{2} \mathrm{CzOCF}_{3}, \mathbf{2} \mathrm{CzSCF}_{3}$, and $2 \mathrm{CzSF}_{5}$ (isovalue $=0.02$ ).
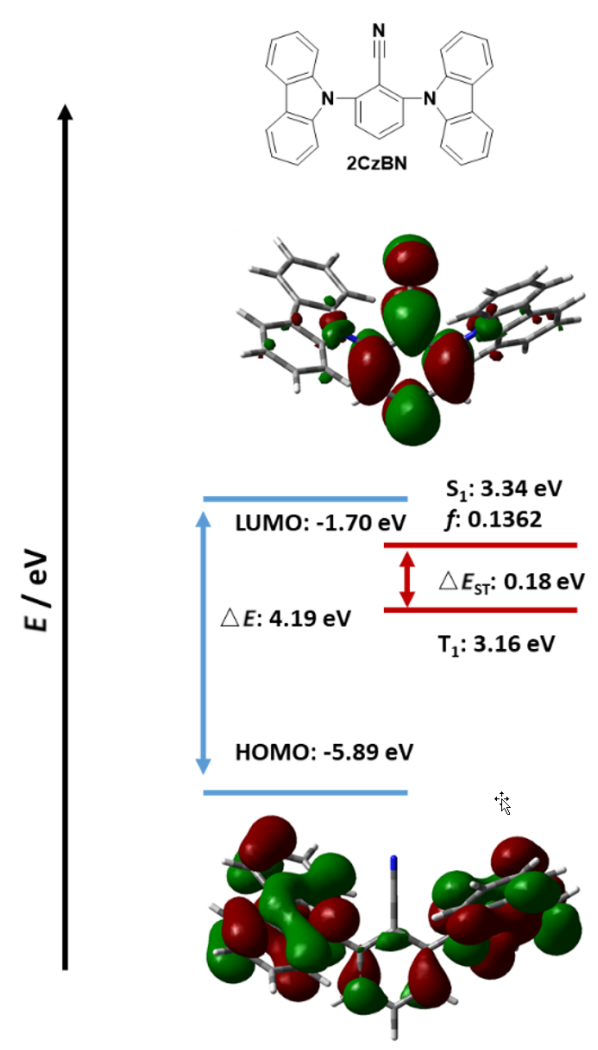
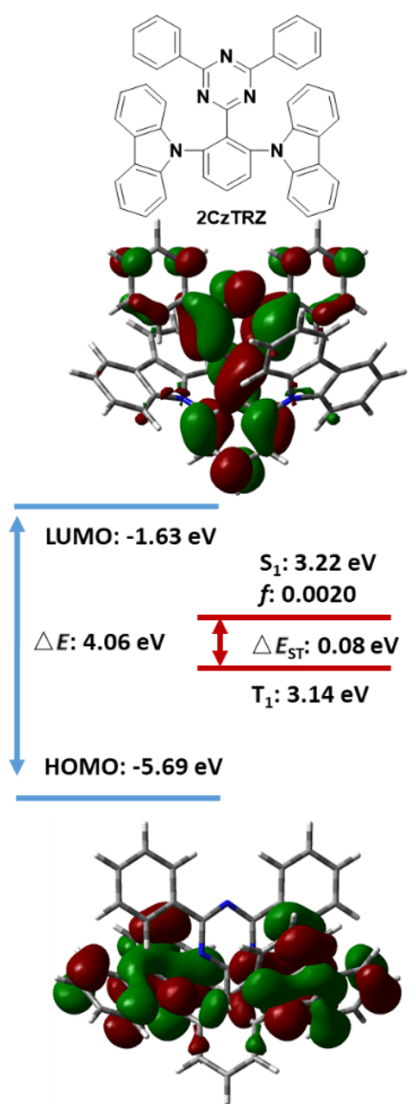
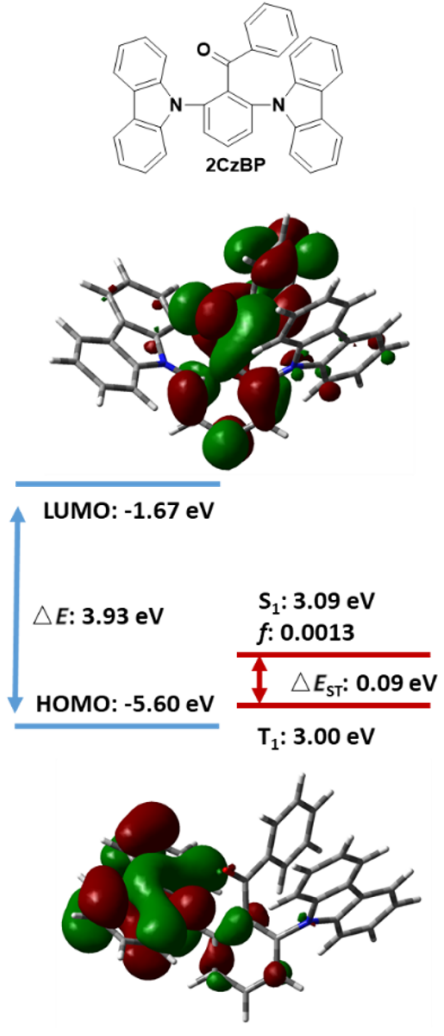

Figure 4: Calculated HOMO, LUMO, $\mathrm{S}_{1}$ and $\mathrm{T}_{1}$ energies, as well as $\mathrm{HOMO}$ and LUMO topologies of $\mathbf{2 C z B N}, \mathbf{2 C z T R Z}$, and $\mathbf{2 C z B P}$ (isovalue $=0.02$ ). 


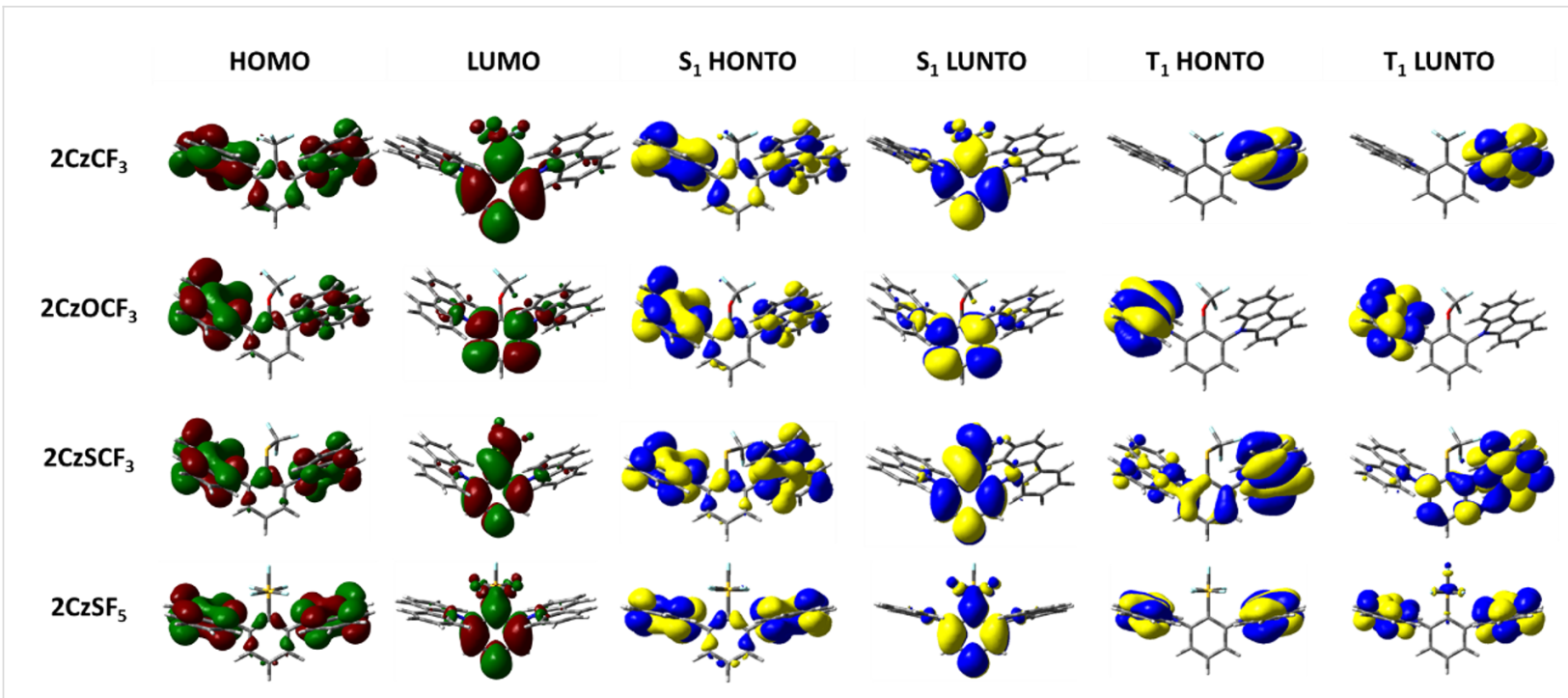

Figure 5: $\mathrm{HOMO}$ and LUMO distribution, $\mathrm{HONTO}$ and LUNTO of lowest singlet $\left(\mathrm{S}_{1}\right)$ and triplet excited $\left(\mathrm{T}_{1}\right)$ states for compounds $2 \mathrm{Cz}_{2} \mathrm{CF}_{3}, 2 \mathrm{CzOCF}_{3}$, $2 \mathrm{CzSCF}_{3}$, and $2 \mathrm{CzSF}_{5}$ (isovalue $=0.02$ ).

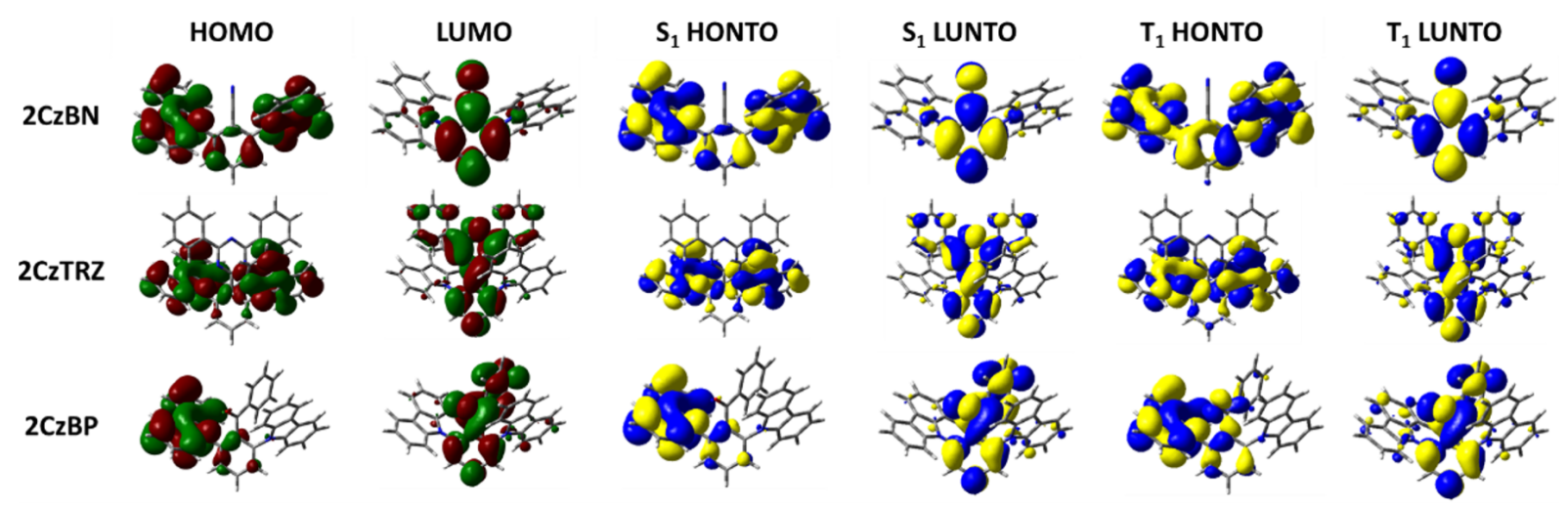

Figure 6: HOMO and LUMO distribution, HONTO and LUNTO of lowest singlet $\left(\mathrm{S}_{1}\right)$ and triplet excited $\left(\mathrm{T}_{1}\right)$ states for compounds $2 \mathrm{CzBN}, 2 \mathrm{CzTRZ}$, and 2CzBP (isovalue $=0.02$ ).

The nature of the $\mathrm{T}_{1}$ state of $\mathbf{2 C z C F}_{3}, \mathbf{2 C z O C F}_{3}$, and $\mathbf{2 \mathrm { CzSF } _ { 5 }}$ is of locally excited (LE) character on the carbazole, while for $\mathbf{2 C z S C F}_{3}$ the $\mathrm{T}_{1}$ state is also LE, but also involving the bridging benzene ring. These assignments are reflected in very similar $\mathrm{T}_{1}$ energies of around $3.45 \mathrm{eV}$. The corresponding $\Delta E_{\mathrm{ST}}$ values are $0.17 \mathrm{eV}$ for $\mathbf{2 C z C F}_{\mathbf{3}}, 0.46 \mathrm{eV}$ for $\mathbf{2 C z O C F}_{\mathbf{3}}, 0.22 \mathrm{eV}$ for $\mathbf{2 z S C F}_{3}$ and $0.07 \mathrm{eV}$ for $\mathbf{2 C z S F}_{5}$; thus, with the exception of $\mathbf{2 Z z O C F}_{3}$, the small singlet-triplet energy gaps coupled with the large difference in symmetry between $S_{1}$ and $T_{1}$ augers well for efficient deep blue TADF emitters. By contrast, the triplet states of 2CzBN, 2CzTRZ, and 2CzBP are best characterized by HOMO to LUMO CT-type transition. The calculated $\mathrm{T}_{1}$ values for 2CzBN, 2CzTRZ, and 2CzBP are $3.16 \mathrm{eV}, 3.14 \mathrm{eV}$, and $3.00 \mathrm{eV}$, respectively. These values are slightly destabi- lized compared to the literature reported values for $2 \mathbf{C z B N}$ (3.03 eV in toluene [19]) and 2CzTRZ (3.05 eV in zeonex [20]). The corresponding $\Delta E_{\mathrm{ST}}$ values are generally smaller than those of the Type I fluorinated compounds with values of $0.08 \mathrm{eV}$ for 2CzTRZ, $0.09 \mathrm{eV}$ for 2CzBP and $0.18 \mathrm{eV}$ for 2CzBN; however, the similar orbital symmetries between $\mathrm{S}_{1}$ and $\mathrm{T}_{1}$ would render rISC between these two states less efficient. The calculated $\Delta E_{\mathrm{ST}}$ values are close to the literature reported values for 2CzBN (0.27 eV in toluene [19]) and 2CzTRZ (0.07 eV in zeonex [20]).

Inspired by these results, we next extended our theoretical study to Type II compounds where we increased the number of carbazole donor groups from two to five. We expect this design 
to lead to improved spatial separation of the electron density distributions between the HOMO and LUMO, thereby strengthening the $\mathrm{CT}$ character of the $\mathrm{S}_{1}$ state and leading to smaller
$\Delta E_{\mathrm{ST}}$ values, and thus more efficient TADF. The HOMO and LUMO distributions and energies for the Type II emitters are shown in Figure 7 and Figure 8. The HOMOs of $\mathbf{5 C z C F}_{\mathbf{3}}$,

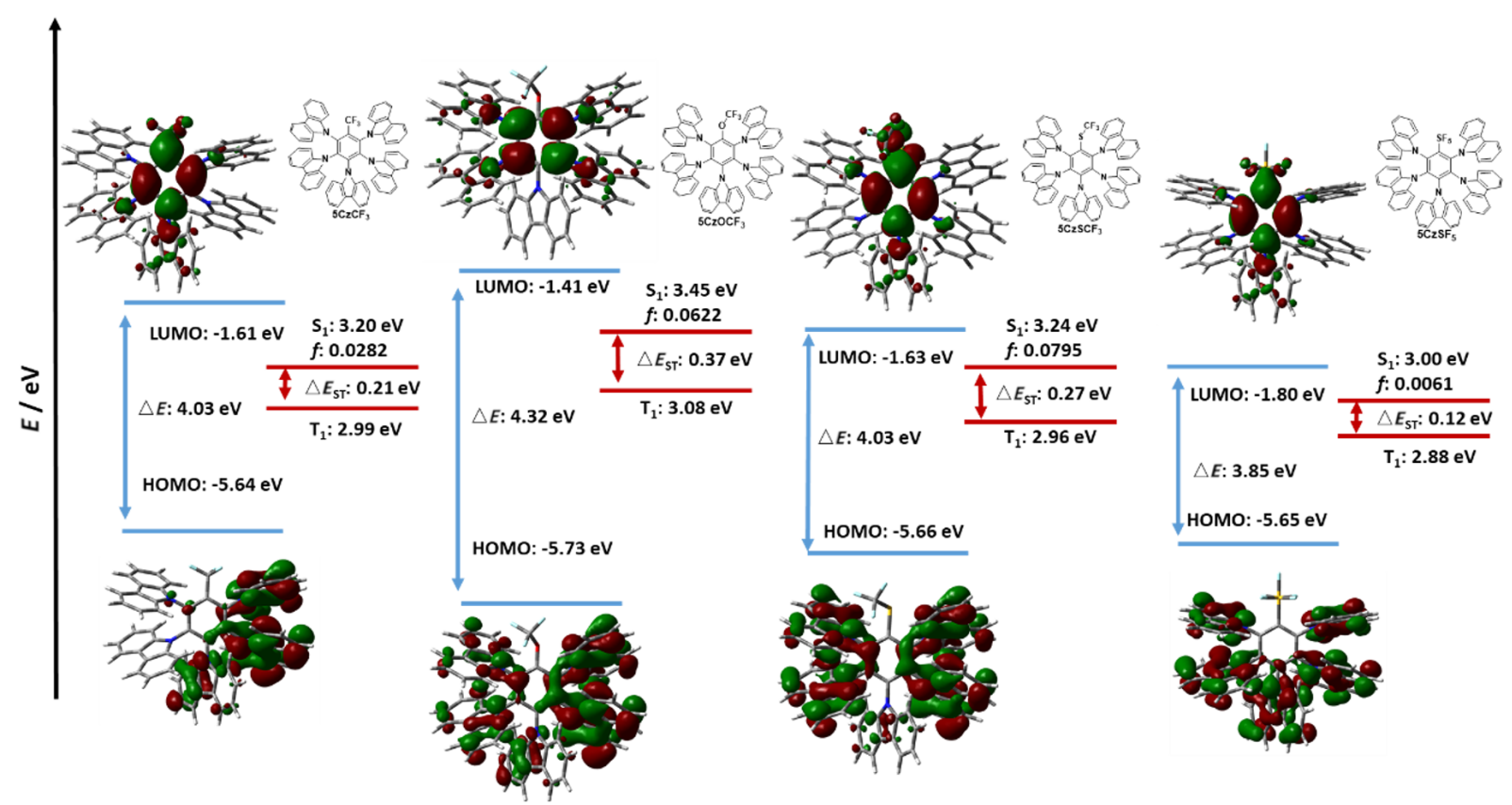

Figure 7: Calculated HOMO, LUMO, $\mathrm{S}_{1}$ and $\mathrm{T}_{1}$ energies, as well as $\mathrm{HOMO}$ and $\mathrm{LUMO}$ topologies of $\mathbf{5} \mathrm{CzCF}_{\mathbf{3}}, \mathbf{5} \mathrm{CzOCF}_{\mathbf{3}}, \mathbf{5} \mathrm{CzSCF}_{\mathbf{3}}$, and $\mathbf{5} \mathrm{CzSF}_{\mathbf{5}}$ (isovalue $=0.02$ ).

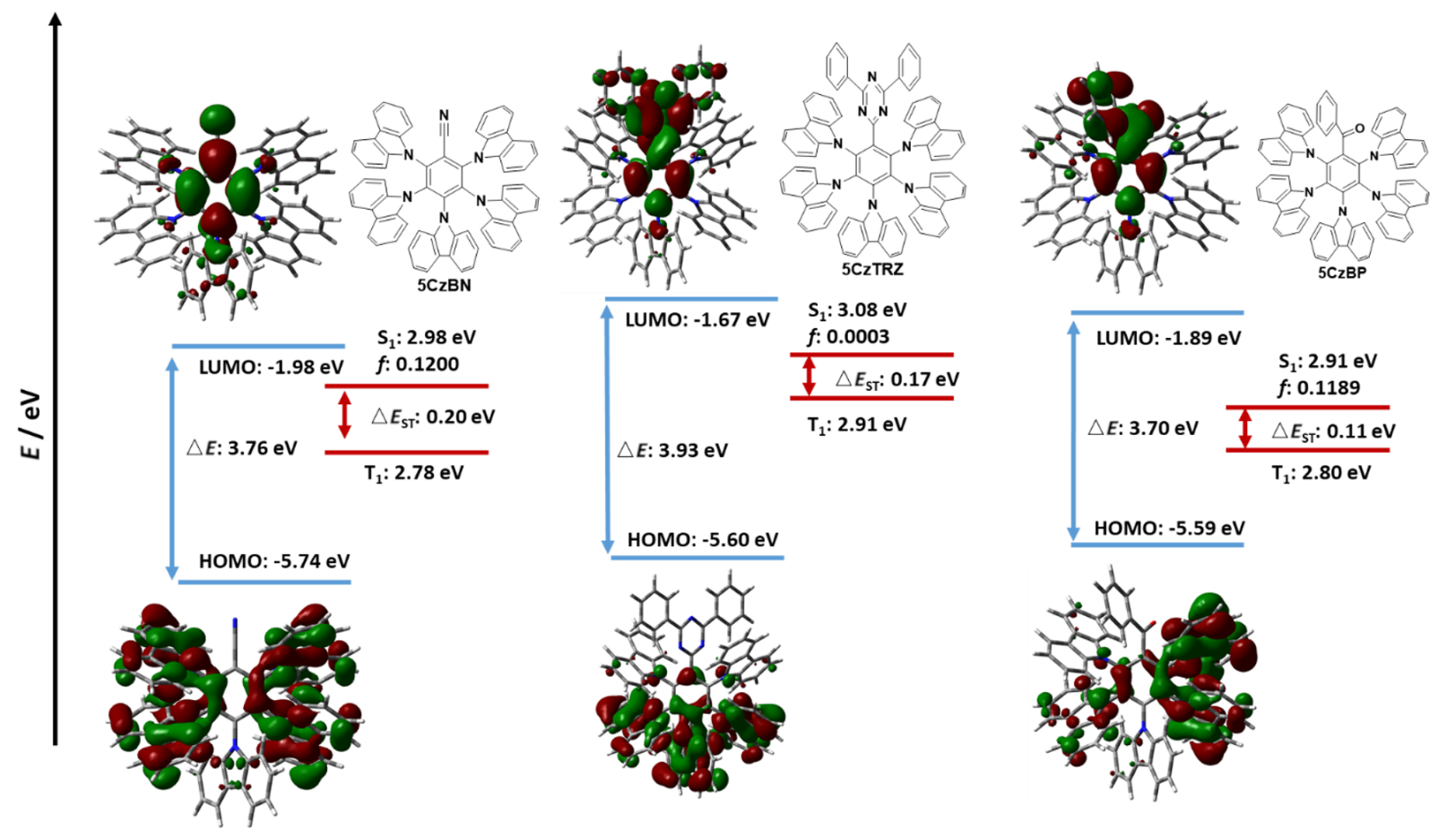

Figure 8: Calculated HOMO, LUMO, $\mathrm{S}_{1}$ and $\mathrm{T}_{1}$ energies, as well as HOMO and LUMO topologies of $5 \mathbf{C z B N}, \mathbf{5 C z T R Z}$, and $\mathbf{5 C z B P}$ (isovalue $=0.02$ ). 
$\mathbf{5 C z O C F}_{3}$, and $\mathbf{5 C z S C F}_{3}$ are mainly located on the carbazole moieties located ortho and meta to the acceptor group, with only a small distribution on the para-carbazole. For $\mathbf{5 C z S F}_{\mathbf{5}}$, the HOMO is evenly distributed over the five carbazole moieties. The LUMOs of $\mathbf{5 C z C F}_{\mathbf{3}}, \mathbf{5 C z S C F}_{\mathbf{3}}$, and $\mathbf{5 C z S F}_{\mathbf{5}}$ are mainly located on the bridging benzene ring and the electronwithdrawing groups along with a small contribution from the para-disposed carbazole, whereas the LUMO of $\mathbf{5 C z O C F}_{\mathbf{3}}$ is located only on the central benzene ring, a similar behavior to $\mathbf{2 C z O C F}_{\mathbf{3}}$. Compounds $\mathbf{5} \mathrm{CzCF}_{\mathbf{3}}, \mathbf{5 C z S C F}_{\mathbf{3}}$, and $\mathbf{5} \mathrm{CzSF}_{\mathbf{5}}$ showed similarly deep HOMO values of around $-5.65 \mathrm{eV}$, while the HOMO value of $\mathbf{5 C z O S F}_{\mathbf{3}}$ is more stabilized at $-5.73 \mathrm{eV}$. The $\mathbf{5 C z O C F}_{3}$ possesses the most destabilized LUMO level at $-1.41 \mathrm{eV}$, while $\mathbf{5 C z S F}_{\mathbf{5}}$ possesses the deepest LUMO level at $-1.80 \mathrm{eV}$. The LUMO values for $\mathbf{5 C z C F}_{\mathbf{3}}$ and $\mathbf{5 C z S C F}_{\mathbf{3}}$ are $-1.61 \mathrm{eV}$ and $-1.63 \mathrm{eV}$, respectively. $\mathbf{5 C z O C F}_{\mathbf{3}}$ has, therefore, the largest energy gap $\left(\Delta E_{\mathrm{g}}\right)$ at $4.32 \mathrm{eV}$ while $\mathbf{5 C z S F}_{\mathbf{5}}$ has the smallest at $3.85 \mathrm{eV}$; both $\mathbf{5 C z C F}_{\mathbf{3}}$ and $\mathbf{5 C z O C F}_{3}$ possess $\Delta E_{\mathrm{g}}$ of $4.03 \mathrm{eV}$. The trends for the HOMO and LUMO energies for these five Type II emitters mirror those observed for their Type I analogues; however, the HOMO and LUMO values in the Type II emitters are more stabilized and the energy gaps are reduced.

The HOMO of $\mathbf{5 C z B N}$ is symmetrically distributed across the ortho- and meta-disposed carbazoles while the HOMO of 5CzTRZ is located mostly on the meta- and para-carbazoles. For 5CzBP, due to the asymmetric structure, the HOMO is lo- cated on one side of ortho- and meta-disposed carbazoles while the pseudo-degenerate HOMO-1 is located on the other orthoand meta-disposed carbazoles. The LUMOs of $\mathbf{5 C z B N}, \mathbf{5 C z B P}$, and 5CzTRZ are each located on the central benzene ring and extending onto the electron-withdrawing group. The HOMO of 5CzBN is deepest at $-5.74 \mathrm{eV}$, similar to that calculated for $\mathbf{5 C z O C F}_{3}$, while the HOMOs of $5 \mathrm{CzBP}$ and $\mathbf{5 C z T R z}$ are -5.59 and $-5.60 \mathrm{eV}$, respectively. The LUMO values of 5CzBN, and $5 \mathbf{C z B P}$ are $-1.98 \mathrm{eV}$, and $-1.89 \mathrm{eV}$, respectively, which are significantly more stabilized than the fluorinated Type II emitters while the LUMO of 5CzTRZ at $-1.67 \mathrm{eV}$ is similar to those predicted for $\mathbf{5 C z C F}_{\mathbf{3}}(-1.61 \mathrm{eV})$ and $\mathbf{5 C z S C F}_{\mathbf{3}}$ $(-1.63 \mathrm{eV})$. The $\Delta E_{\mathrm{g}}$ values of $\mathbf{5 C z B N}(3.76 \mathrm{eV}), \mathbf{5 C z T R Z}$ $(3.93 \mathrm{eV})$, and $\mathbf{5 C z B P}(3.70 \mathrm{eV})$ are all slightly smaller than those of the fluorinated Type II emitters.

The HONTOs and LUNTOs for the Type II emitters are shown in Figure 9 and Figure 10. These generally reflect the HOMO and LUMO distributions, save for 5CzTRZ where the HONTO of $S_{1}$ is located on the ortho-carbazoles. Due to the sufficiently large separation of the electron densities between the HOMO and LUMO of each of the seven Type II emitters, the $S_{1}$ state for each of these possesses CT character, analogously to those calculated for the Type I compounds. $\mathbf{5 C z O C F}_{3}$ possesses the highest $\mathrm{S}_{1}$ energy $(3.45 \mathrm{eV})$ among Type II molecules, followed by $\mathbf{5 C z S C F}_{\mathbf{3}}(3.24 \mathrm{eV})$ and $\mathbf{5 C z C F}_{\mathbf{3}}(3.20 \mathrm{eV})$. The $\mathrm{S}_{1}$ of $\mathbf{5 C z S F}_{5}$ is $3.00 \mathrm{eV}$, which is close to the values of $\mathbf{5 C z B N}$ $(2.98 \mathrm{eV}), \mathbf{5 C z T R Z}(3.08 \mathrm{eV})$ and 5CzBP $(2.91 \mathrm{eV})$. The
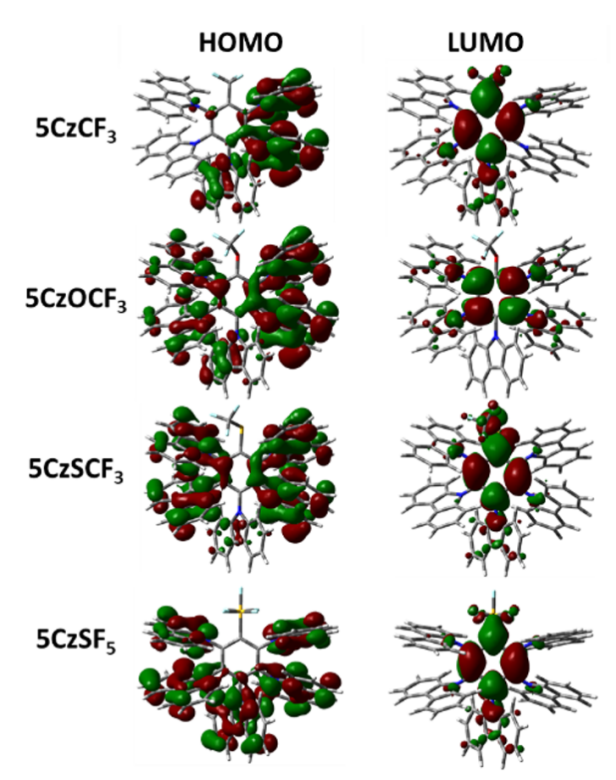
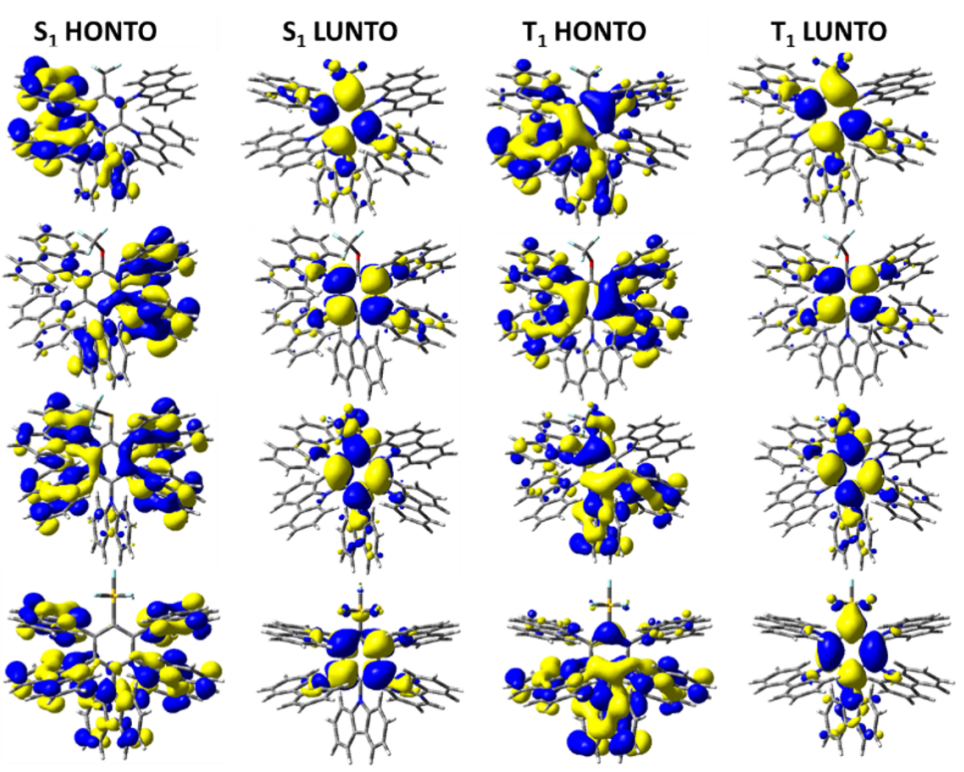

Figure 9: HOMO and LUMO distribution, HONTO and LUNTO of lowest singlet $\left(\mathrm{S}_{1}\right)$ and triplet excited $\left(\mathrm{T}_{1}\right)$ states for compounds $5 \mathrm{CzCF}_{3}, 5 \mathrm{CzOCF}_{3}$, $5 \mathrm{CzSCF}_{3}$, and $5 \mathrm{CzSF}_{5}$ (isovalue $=0.02$ ). 


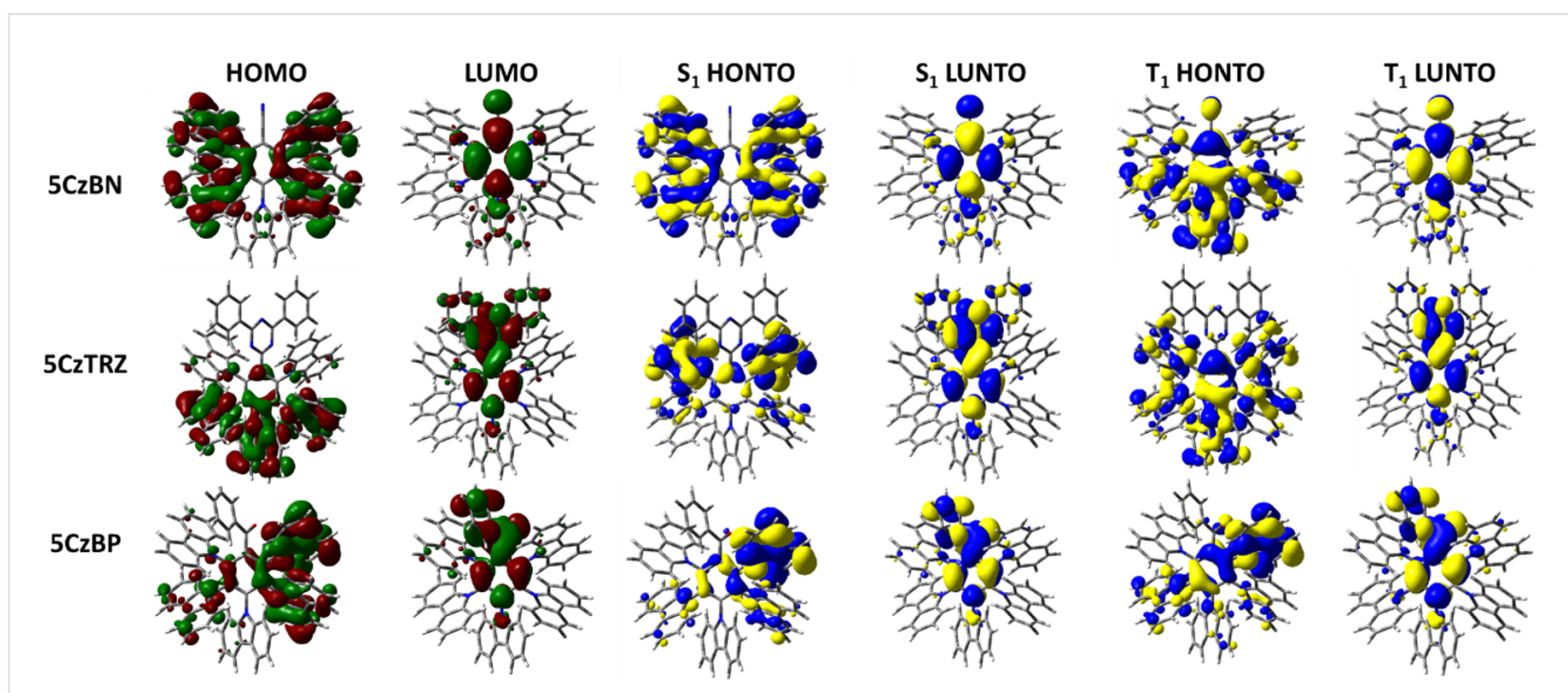

Figure 10: HOMO and LUMO distribution, HONTO and LUNTO of lowest singlet $\left(\mathrm{S}_{1}\right)$ and triplet excited $\left(\mathrm{T}_{1}\right)$ states for compounds 5 CzBN, 5CzTRZ, and 5CzBP (isovalue $=0.02$ ).

calculated $\mathrm{S}_{1}$ values are more destabilized than the literature reported values of $\mathbf{5 C z B N}$ (2.90 eV in toluene [23]), 5CzTRZ (2.85 eV in toluene [24]) and $\mathbf{5} \mathbf{C z C F}_{\mathbf{3}}(2.82 \mathrm{eV}$ in toluene [25]). The nature of the $T_{1}$ state for each of these compounds is CT where the HONTOs of $\mathrm{T}_{1}$ are mainly located on the carbazole moieties (and sometimes the central benzene) while the LUNTOs of $\mathrm{T}_{1}$ are mainly located on the benzene ring and electron-withdrawing groups, except for $\mathbf{5 C z O C F}_{3}$ where the LUNTO is located only on the benzene. $\mathbf{5 C z O C F}_{\mathbf{3}}$ possesses the highest $\mathrm{T}_{1}$ energy $(3.08 \mathrm{eV})$, while the $\mathrm{T}_{1}$ energies of $\mathbf{5 C z C F}_{\mathbf{3}}, \mathbf{5 C z S C F}_{\mathbf{3}}$, and $\mathbf{5 C z S F}_{\mathbf{5}}$ are stabilized at $2.99 \mathrm{eV}$, $2.96 \mathrm{eV}$, and $2.88 \mathrm{eV}$, respectively. The $\mathrm{T}_{1}$ energy of $\mathbf{5 C z T R Z}$ is $2.91 \mathrm{eV}$ while those of $\mathbf{5 C z B N}$ and $\mathbf{5 C z B P}$ are more stabilized at $2.78 \mathrm{eV}$ and $2.80 \mathrm{eV}$, respectively. The calculated $\mathrm{T}_{1}$ energies match the literature reported value of $\mathbf{5 C z B N}(2.78 \mathrm{eV}$ in toluene [23]) and are slightly destabilized relative to the literature reported value of $\mathbf{5 C z T R Z}$ (2.79 eV in toluene [24]) and $\mathbf{5 C z C F}_{\mathbf{3}}$ (2.82 eV in toluene [25]). The corresponding $\Delta E_{\mathrm{ST}}$ value of $\mathbf{5 C z O C F}_{\mathbf{3}}$ is $0.37 \mathrm{eV}$, which is reduced by $0.11 \mathrm{eV}$ compared to $\mathbf{2 C z O C F}_{3}(0.46 \mathrm{eV})$. This reduction results from the greater CT character in both $S_{1}$ and $T_{1}$. However, as the HOMO/LUMO overlap includes a small distribution on paradisposed carbazole in the Type II emitters with the exception of $\mathbf{5 C z O C F}_{3}$, the $\Delta E_{\mathrm{ST}}$ values of Type II emitters are generally slightly larger compared to their Type I congeners. The $\Delta E_{\mathrm{ST}^{\mathrm{S}}}$ of $\mathbf{5 C z C F}_{\mathbf{3}}, \mathbf{5 C z S C F}_{\mathbf{3}}$ and $\mathbf{5 C z S F}_{\mathbf{5}}$ are $0.21 \mathrm{eV}, 0.27 \mathrm{eV}$, and $0.12 \mathrm{eV}$, respectively, which are $0.04 \mathrm{eV}, 0.05 \mathrm{eV}$, and $0.05 \mathrm{eV}$, respectively larger compared to $\mathbf{2 C z C F}_{\mathbf{3}}(0.17 \mathrm{eV}), \mathbf{2 C z S C F}_{\mathbf{3}}$ $(0.22 \mathrm{eV})$, and $2 \mathbf{C z S F}_{\mathbf{5}}(0.07 \mathrm{eV})$. The $\Delta E_{\mathrm{ST}}$ s of $\mathbf{5 C z B N}$ and 5CzBP are $0.20 \mathrm{eV}$ and $0.11 \mathrm{eV}$, which are only $0.02 \mathrm{eV}$ larger compared to $\mathbf{2 C z B N}(0.18 \mathrm{eV})$ and $\mathbf{2 C z B P}(0.09 \mathrm{eV})$, while the
$\Delta E_{\mathrm{ST}}$ for $\mathbf{5 C z T R Z}$ is $0.17 \mathrm{eV}$, which is $0.09 \mathrm{eV}$ larger than that of 2CzTRZ $(0.08 \mathrm{eV})$. The calculated $\Delta E_{\mathrm{ST}}$ values are slightly larger than the literature reported values for $\mathbf{5 C z B N}(0.12 \mathrm{eV}$ in toluene [23]) and 5CzTRZ (0.06 eV in toluene [24]).

The spin-orbit coupling (SOC) values between excited singlet and triplets were calculated by considering the three $\mathrm{T}_{1}$ substates $(m=0, \pm 1)$ are degenerate and the $\left|V_{\text {SOC }}\right|^{2}$ as the average of the three spin-orbit coupling matrix elements (SOCME) between singlet and the triplet states [36]. The results are summarized in Table 1. Among the Type I molecules, $\mathbf{2 C z S C F}_{3}$ possesses the highest $\left|V_{\mathrm{SOC}}\right|^{2}$ value as $0.148 \mathrm{~cm}^{-2}$, followed by 2CzBP $\left(0.070 \mathrm{~cm}^{-2}\right)$ and $2 \mathrm{CzSF}_{5}\left(0.053 \mathrm{~cm}^{-2}\right)$. The $\left|V_{\text {SOC }}\right|^{2}$

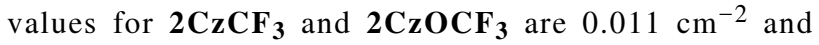
$0.019 \mathrm{~cm}^{-2}$, respectively, which are still much higher than 2CzBN $\left(0.002 \mathrm{~cm}^{-2}\right)$ and 2 CzTRZ $\left(3 \times 10^{-4} \mathrm{~cm}^{-2}\right)$. The Type II molecules show an increase in $\left|V_{\text {SOC }}\right|^{2}$ values compared to their Type I counterparts. $\mathbf{5 C z S C F}_{\mathbf{3}}$ possesses the highest $\left|V_{\text {SOC }}\right|^{2}$ value at $0.750 \mathrm{~cm}^{-2}$ which is five times higher than $\mathbf{2 C z S F}_{\mathbf{5}}$, and $\mathbf{5 C z S F}_{\mathbf{5}}$ possesses the second highest $\left|V_{\text {SOC }}\right|^{2}$ value as $0.718 \mathrm{~cm}^{-2}$, which is more than thirteen times higher than $\mathbf{2 C z S F}_{\mathbf{5}}$. The higher $\left|V_{\mathrm{SOC}^{2}}\right|^{2}$ values of $\mathbf{2 C z S C F}_{\mathbf{3}} / \mathbf{5 C z S C F}_{\mathbf{3}}$ and $\mathbf{2 C z S F}_{5} / \mathbf{5 C z S F}_{5}$ can be ascribed to the presence of the relatively heavier chalcogen, which has also been attributed by Duan et al. to much higher SOCME values in a sulfur-containing emitter than in analogs without the sulfur atom present [37]. The $\left|V_{\text {SOC }}\right|^{2}$ values of $5 \mathbf{C z B N}$ and $5 \mathbf{C z B P}$ increased to $0.298 \mathrm{~cm}^{-2}$ and $0.267 \mathrm{~cm}^{-2}$, respectively, which are more than one hundred times higher than $\mathbf{2 C z B N}$ and four times higher than $\mathbf{2 C z B P}$. The $\left|V_{\text {SOC }}\right|^{2}$ values of $\mathbf{5 C z C F}_{\mathbf{3}}$ and $\mathbf{5 C z O C F}_{\mathbf{3}}$ are also higher at $0.090 \mathrm{~cm}^{-2}$ and $0.060 \mathrm{~cm}^{-2}$, respectively. The 
Table 1: $\mathrm{S}_{1}$ and $\mathrm{T}_{1}$ energies, $\Delta E_{\mathrm{ST}}$, and average $\left|V_{\mathrm{SOC}}\right|^{2}$ values of Type I and Type II molecules.

\begin{tabular}{|c|c|c|c|c|c|}
\hline Compound & $\mathrm{S}_{1}[\mathrm{eV}]$ & $\mathrm{T}_{1}[\mathrm{eV}]$ & $\Delta E_{\mathrm{ST}}[\mathrm{eV}]$ & $\left|V_{\mathrm{SOCl}}\right|^{2}\left[\mathrm{~cm}^{-2}\right]$ & $\left|V_{\mathrm{SOC}}\right|^{2} \times \exp \left[-\left(\Delta E_{\mathrm{ST}}{ }^{2}\right)\right]$ \\
\hline $2 \mathrm{CzCF}_{3}$ & 3.62 & 3.45 & 0.17 & 0.011 & $1.48 \times 10^{-10}$ \\
\hline $2 \mathrm{CzOCF}_{3}$ & 3.92 & 3.46 & 0.46 & 0.019 & $2.20 \times 10^{-10}$ \\
\hline $2 \mathrm{CzSCF}_{3}$ & 3.66 & 3.44 & 0.22 & 0.148 & $2.03 \times 10^{-9}$ \\
\hline $2 \mathrm{CzSF}_{5}$ & 3.51 & 3.44 & 0.07 & 0.053 & $7.54 \times 10^{-10}$ \\
\hline 2CzBN & 3.34 & 3.16 & 0.18 & 0.002 & $3.07 \times 10^{-11}$ \\
\hline $2 \mathrm{CzBP}$ & 3.22 & 3.14 & 0.08 & 0.070 & $1.00 \times 10^{-9}$ \\
\hline 2CzTRZ & 3.09 & 3.00 & 0.09 & $3 \times 10^{-4}$ & $4.29 \times 10^{-12}$ \\
\hline $5 \mathrm{CzCF}_{3}$ & 3.20 & 2.99 & 0.21 & 0.090 & $1.24 \times 10^{-9}$ \\
\hline $5 \mathrm{CzOCF}_{3}$ & 3.45 & 3.08 & 0.37 & 0.060 & $7.51 \times 10^{-10}$ \\
\hline $5 \mathrm{CzSCF}_{3}$ & 3.24 & 2.96 & 0.27 & 0.750 & $1.00 \times 10^{-8}$ \\
\hline $5 \mathrm{CzSF}_{5}$ & 3.00 & 2.88 & 0.12 & 0.718 & $1.02 \times 10^{-8}$ \\
\hline $5 \mathrm{CzBN}$ & 2.98 & 2.78 & 0.20 & 0.298 & $4.12 \times 10^{-9}$ \\
\hline 5CzBP & 3.08 & 2.91 & 0.17 & 0.267 & $3.74 \times 10^{-9}$ \\
\hline 5CzTRZ & 2.91 & 2.80 & 0.11 & 0.001 & $1.57 \times 10^{-11}$ \\
\hline
\end{tabular}

$\left|V_{\mathrm{SOCl}}\right|^{2}$ value of $\mathbf{5 C z T R Z}$ also increased to $0.001 \mathrm{~cm}^{-2}$ from $3 \times 10^{-4} \mathrm{~cm}^{-2}$ for $\mathbf{2 C z T R Z}$; however, the predicted $\left|V_{\mathrm{SOC}}\right|^{2}$ value between $S_{1}$ and $T_{2}\left(0.107 \mathrm{~cm}^{-2}\right)$ is much higher (Table $\mathbf{S} 14$, Supporting Information File 1). A measure of the magnitude of $k_{\mathrm{rISC}}$ can be ascertained from $\left|V_{\mathrm{SOCl}}\right|^{2} \times \exp \left[-\left(\Delta E_{\mathrm{ST}^{2}}\right)\right]$. The trends align here are consistent with the SOCME calculations. By comparison, the experimentally inferred $k_{\mathrm{rISC}}$ for 2CzBN, 5CzBN and 5CzTRZ are $0.86 \times 10^{5} \mathrm{~s}^{-1}$ in DPEPO film [21], $2.2 \times 10^{5} \mathrm{~s}^{-1}$ in toluene [22], and $1.5 \times 10^{7} \mathrm{~s}^{-1}$ in toluene [24], respectively. The trend in experimental $k_{\mathrm{rISC}}$ for $2 \mathrm{CzBN}$ and $\mathbf{5 C z B N}$ match our SOCME calculations as 5CzBN possesses the third highest $\left|V_{\mathrm{SOC}}\right|^{2} \times \exp \left[-\left(\Delta E_{\mathrm{ST}}{ }^{2}\right)\right]$ while $\mathbf{2 C z B N}$ has the third lowest value. Clearly, for $\mathbf{5 C z T R Z}$ there is a lack of correlation between the computed $\left|V_{\mathrm{SOCl}}\right|^{2} \times \exp \left[-\left(\Delta E_{\mathrm{ST}}{ }^{2}\right)\right]$ and the experimentally determined $k_{\mathrm{rISC}}$ values. The significantly higher experimental $k_{\mathrm{rISC}}$ can be explained by the presence of intermediate triplet states leading to second order spin-vibronic coupling to mediate rISC in 5CzTRZ [24]; indeed, the $\left|V_{\text {SOC }}\right|^{2}$ value was predicted to be much higher by the SOCME calculations between $S_{1}$ and $T_{2}$ at $0.107 \mathrm{~cm}^{-2}$.

Prior studies on $\mathbf{5 C z B N}$ and $\mathbf{5 C z T R Z}$ showed that intermediate excited states between $S_{1}$ and $T_{1}$ can facilitate the rISC process by providing extra rISC transition channels from the higher intermediate excited triplet states to $S_{1}$ thereby improving the rISC rate [22,24]. The presence of multiple donors, each possessing slightly different conformations, and thereby presenting slightly different electronic coupling with the central acceptor guarantees a dense population of excited states [22,24]. We analysed the higher excited states of the fluorinated acceptor-containing emitters in both Type I and Type II structures. For $\mathbf{2 C z C F}_{3}$, the $\mathrm{T}_{1}$ is locally excited; further, $\mathrm{T}_{2}(3.46 \mathrm{eV})$ to $\mathrm{T}_{6}(3.58 \mathrm{eV})$ all exhibited significant LE character. The lowest triplet state that exhibits charge transfer characteristics is $\mathrm{T}_{7}$ at $3.72 \mathrm{eV}$ (Figure 11). By contrast, the $\mathrm{T}_{1}$ of $\mathbf{5 C z C F}_{3}$ exhibited $\mathrm{CT}$ character and the higher triplet states from $\mathrm{T}_{2}$ to $\mathrm{T}_{6}$ also exhibited $\mathrm{CT}$ character, which is a similar picture to the literature reported calculated electronic structure of 5CzBN using TD-DFT/wB97XD [22] (Figure 12). This change from mostly low-lying LE triplet states in Type I emitters to mostly low-lying CT states in Type II emitters is prevalent in $\mathbf{2 C z O C F}_{\mathbf{3}} / \mathbf{5} \mathrm{CzOCF}_{3}, \mathbf{2} \mathrm{CzSCF}_{\mathbf{3}} / \mathbf{5} \mathrm{CzSCF}_{3}$, and $\mathbf{2 C z S F}_{\mathbf{5}} / \mathbf{5 C z S F}_{5}$ (Figures S1-S6, Supporting Information File 1). Both Type I and Type II molecules are predicted to possess multiple intermediate excited states between $S_{1}$ and $T_{1}$. For example, for $\mathbf{2 C z C F}_{3} \mathrm{~T}_{2}$ to $\mathrm{T}_{6}$ lie between $\mathrm{S}_{1}$ and $\mathrm{T}_{1}$ and the energy gap between $\mathrm{T}_{6}$ and $\mathrm{S}_{1}\left(\Delta E_{\mathrm{S} 1 \mathrm{~T} 6}\right)$ is $0.04 \mathrm{eV}$ while for $\mathbf{5 C z C F}_{3}$ the $\mathrm{T}_{2}$ to $\mathrm{T}_{4}$ are intermediate states with energies below $\mathrm{S}_{1}$ and the energy gap between $\mathrm{T}_{4}$ and $\mathrm{S}_{1}\left(\Delta E_{\mathrm{S} 1 \mathrm{~T} 4}\right)$ is $0.02 \mathrm{eV}$. This phenomenon is also observed in $\mathbf{2 C z O C F}_{3}$ $\left(\Delta E_{\mathrm{S} 1 \mathrm{~T} 6}=0.08 \mathrm{eV}\right) / \mathbf{5 C z O C F}_{\mathbf{3}}\left(\Delta E_{\mathrm{S} 1 \mathrm{~T} 8}=0.02 \mathrm{eV}\right)$, and $\mathbf{2 C z S C F}_{\mathbf{3}}\left(\Delta E_{\mathrm{S} 1 \mathrm{~T} 6}=0.09 \mathrm{eV}\right) / \mathbf{5 C z S C F}_{\mathbf{3}}\left(\Delta E_{\mathrm{S} 1 \mathrm{~T} 4}=0.00 \mathrm{eV}\right)$, $\mathbf{2 C z S F}_{5}\left(\Delta E_{\mathrm{S} 1 \mathrm{~T} 3}=0.01 \mathrm{eV}\right) / \mathbf{5 C z C F}_{\mathbf{3}}\left(\Delta E_{\mathrm{S} 1 \mathrm{~T} 4}=0.00 \mathrm{eV}\right) . \mathrm{We}$ thus contend that the intermediate excited states present in the fluorinated acceptor-containing emitters will assist in the rISC process, and improve the TADF characteristics, mitigating the somewhat larger $\Delta E_{\mathrm{ST}}$ values in these compounds.

\section{Conclusion}

This computational study demonstrates the high potential of fluorinated acceptors in TADF emitter design. In particular, we 


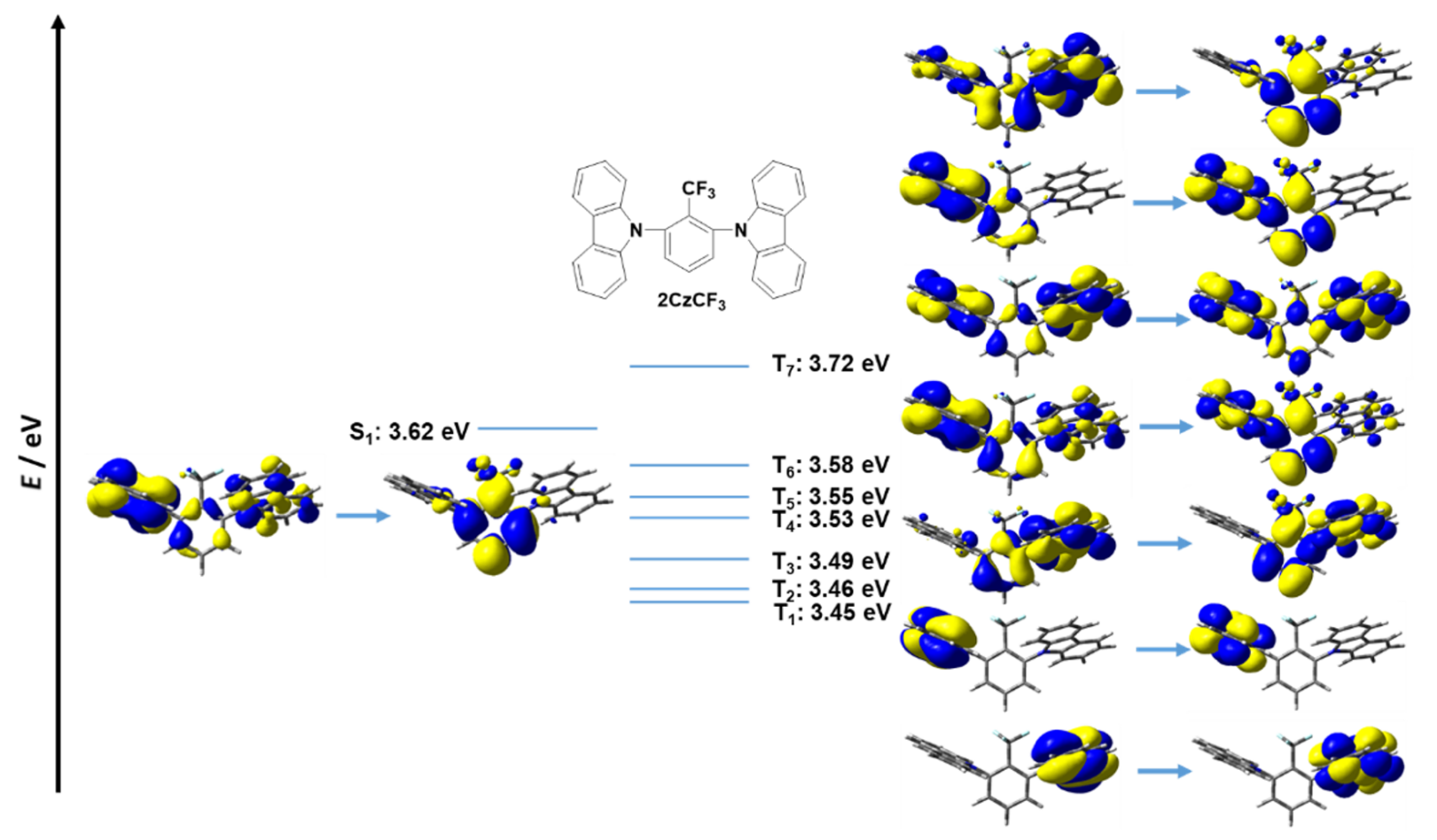

Figure 11: $\mathrm{HONTOs}$ and LUNTOs of $\mathbf{2} \mathrm{CzCF}_{3}$ in higher excited states (isovalue $=0.02$ ).
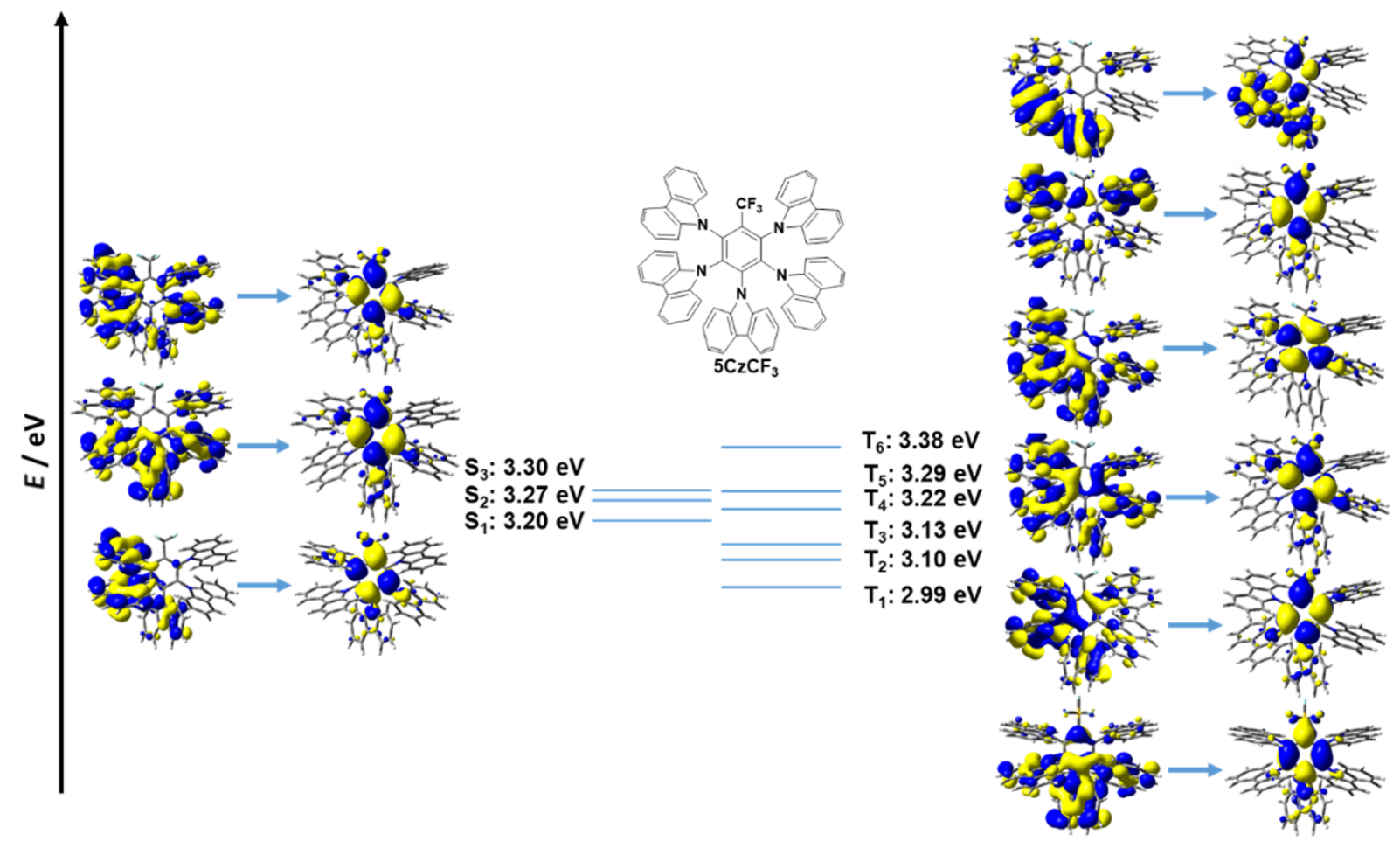

Figure 12: $\mathrm{HONTO}$ and LUNTOs of $5 \mathrm{CzCF}_{3}$ in higher excited states (isovalue $=0.02$ ). 
showed that $\mathrm{OCF}_{3}, \mathrm{SCF}_{3}$ and $\mathrm{SF}_{5}$ groups should all be considered when designing deep blue TADF emitters. Type II emitters, with five carbazole donors, showed the most promise in terms of suitable small $\Delta E_{\mathrm{ST}}$ values, high spin-orbit coupling values coupled with a relatively large density of intermediate excited triplet states that can be recruited to render TADF more efficient. Present efforts are ongoing to synthesize promising candidates from this theoretical study.

\section{Supporting Information}

The research data underpinning this publication can be accessed at https://doi.org/10.17630/b8f9f445-60a0-4c0a-808e-ce27cfc bf 48 a

\section{Supporting Information File 1}

Calculation details, Cartesian coordinates of all the molecules, SOCME calculation result, and HONTOs and

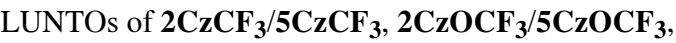
$\mathbf{2 C z S C F}_{\mathbf{3}} / \mathbf{5 C z S C F}_{\mathbf{3}}$, and $\mathbf{2 C z S F}_{\mathbf{5}} / \mathbf{5 C z S F}_{\mathbf{5}}$ in higher-lying excited states are available in supporting information. [https://www.beilstein-journals.org/bjoc/content/ supplementary/1860-5397-17-21-S1.pdf]

\section{Acknowledgements}

We thank Oliver Lee for help with the SOCME calculations.

\section{Funding}

Dongyang Chen thanks the China Scholarship Council (201603780001). We acknowledge support from the Engineering and Physical Sciences Research Council of the United Kingdom (grant EP/P010482/1).

\section{ORCID ${ }^{\circledR} \mathrm{iDs}$}

Eli Zysman-Colman - https://orcid.org/0000-0001-7183-6022

\section{References}

1. Wong, M. Y.; Zysman-Colman, E. Adv. Mater. 2017, 29, 1605444. doi:10.1002/adma.201605444

2. Liu, Y.; Li, C.; Ren, Z.; Yan, S.; Bryce, M. R. Nat. Rev. Mater. 2018, 3 18020. doi:10.1038/natrevmats.2018.20

3. Cai, X.; Su, S.-J. Adv. Funct. Mater. 2018, 28, 1802558. doi:10.1002/adfm.201802558

4. Teng, J.-M.; Wang, Y.-F.; Chen, C.-F. J. Mater. Chem. C 2020, 8, 11340-11353. doi:10.1039/d0tc02682d

5. dos Santos, P. L.; Chen, D.; Rajamalli, P.; Matulaitis, T.; Cordes, D. B.; Slawin, A. M. Z.; Jacquemin, D.; Zysman-Colman, E.; Samuel, I. D. W. ACS Appl. Mater. Interfaces 2019, 11, 45171-45179. doi:10.1021/acsami.9b16952
6. Li, W.; Li, B.; Cai, X.; Gan, L.; Xu, Z.; Li, W.; Liu, K.; Chen, D.; Su, S.-J. Angew. Chem., Int. Ed. 2019, 58, 11301-11305. doi:10.1002/anie.201904272

7. Wang, Y.-K.; Huang, C.-C.; Ye, H.; Zhong, C.; Khan, A.; Yang, S.-Y.; Fung, M.-K.; Jiang, Z.-Q.; Adachi, C.; Liao, L.-S. Adv. Opt. Mater. 2020, 8, 1901150. doi:10.1002/adom.201901150

8. Gibson, J.; Monkman, A. P.; Penfold, T. J. ChemPhysChem 2016, 17, 2956-2961. doi:10.1002/cphc.201600662

9. Etherington, M. K.; Gibson, J.; Higginbotham, H. F.; Penfold, T. J.; Monkman, A. P. Nat. Commun. 2016, 7, 13680. doi:10.1038/ncomms13680

10. Agou, T.; Matsuo, K.; Kawano, R.; Park, I. S.; Hosoya, T.; Fukumoto, H.; Kubota, T.; Mizuhata, Y.; Tokitoh, N.; Yasuda, T. ACS Mater. Lett. 2020, 2, 28-34. doi:10.1021/acsmaterialslett.9b00433

11. Penfold, T. J.; Gindensperger, E.; Daniel, C.; Marian, C. M. Chem. Rev. 2018, 118, 6975-7025. doi:10.1021/acs.chemrev.7b00617

12. Sharma, N.; Spuling, E.; Mattern, C. M.; Li, W.; Fuhr, O.; Tsuchiya, Y.; Adachi, C.; Bräse, S.; Samuel, I. D. W.; Zysman-Colman, E. Chem. Sci. 2019, 10, 6689-6696. doi:10.1039/c9sc01821b

13. Meng, G.; Chen, X.; Wang, X.; Wang, N.; Peng, T.; Wang, S. Adv. Opt. Mater. 2019, 7, 1900130. doi:10.1002/adom.201900130

14. Robinson, G. W.; Frosch, R. P. J. Chem. Phys. 1963, 38, 1187-1203. doi:10.1063/1.1733823

15. Lawetz, V.; Orlandi, G.; Siebrand, W. J. Chem. Phys. 1972, 56, 4058-4072. doi:10.1063/1.1677816

16. Schmidt, K.; Brovelli, S.; Coropceanu, V.; Beljonne, D.; Cornil, J.; Bazzini, C.; Caronna, T.; Tubino, R.; Meinardi, F.; Shuai, Z.; Brédas, J.-L. J. Phys. Chem. A 2007, 111, 10490-10499. doi:10.1021/jp075248q

17. Chen, Z.; Wu, Z.; Ni, F.; Zhong, C.; Zeng, W.; Wei, D.; An, K.; Ma, D.; Yang, C. J. Mater. Chem. C 2018, 6, 6543-6548. doi:10.1039/c8tc01698d

18. Wang, K.; Shi, Y.-Z.; Zheng, C.-J.; Liu, W.; Liang, K.; Li, X.; Zhang, M.; Lin, H.; Tao, S.-L.; Lee, C.-S.; Ou, X.-M.; Zhang, X.-H ACS Appl. Mater. Interfaces 2018, 10, 31515-31525. doi:10.1021/acsami.8b08083

19. Zhang, D.; Cai, M.; Bin, Z.; Zhang, Y.; Zhang, D.; Duan, L. Chem. Sci. 2016, 7, 3355-3363. doi:10.1039/c5sc04755b

20. Oh, C. S.; de Sa Pereira, D.; Han, S. H.; Park, H.-J.; Higginbotham, H. F.; Monkman, A. P.; Lee, J. Y. ACS Appl. Mater. Interfaces 2018, 10, 35420-35429. doi:10.1021/acsami.8b10595

21. Chan, C.-Y.; Cui, L.-S.; Kim, J. U.; Nakanotani, H.; Adachi, C. Adv. Funct. Mater. 2018, 28, 1706023. doi:10.1002/adfm.201706023

22. Noda, H.; Chen, X.-K.; Nakanotani, H.; Hosokai, T.; Miyajima, M.; Notsuka, N.; Kashima, Y.; Brédas, J.-L.; Adachi, C. Nat. Mater. 2019, 18, 1084-1090. doi:10.1038/s41563-019-0465-6

23. Zhang, D.; Cai, M.; Zhang, Y.; Zhang, D.; Duan, L. Mater. Horiz. 2016 , 3, 145-151. doi:10.1039/c5mh00258c

24. Cui, L.-S.; Gillett, A. J.; Zhang, S.-F.; Ye, H.; Liu, Y.; Chen, X.-K.; Lin, Z.-S.; Evans, E. W.; Myers, W. K.; Ronson, T. K.; Nakanotani, H.; Reineke, S.; Bredas, J.-L.; Adachi, C.; Friend, R. H. Nat. Photonics 2020, 14, 636-642. doi:10.1038/s41566-020-0668-z

25. Mei, L.; Hu, J.; Cao, X.; Wang, F.; Zheng, C.; Tao, Y.; Zhang, X.; Huang, W. Chem. Commun. 2015, 51, 13024-13027. doi:10.1039/c5cc04126k

26. Liang, X.; Han, H.-B.; Yan, Z.-P.; Liu, L.; Zheng, Y.-X.; Meng, H.; Huang, W. New J. Chem. 2018, 42, 4317-4323. doi:10.1039/c7nj04482h 
27. Yuan, W.; Yang, H.; Duan, C.; Cao, X.; Zhang, J.; Xu, H.; Sun, N.; Tao, Y.; Huang, W. Chem 2020, 6, 1998-2008.

doi:10.1016/j.chempr.2020.04.021

28. Ward, J. S.; Kukhta, N. A.; dos Santos, P. L.; Congrave, D. G.; Batsanov, A. S.; Monkman, A. P.; Bryce, M. R. Chem. Mater. 2019, 31 , 6684-6695. doi:10.1021/acs.chemmater.9b01184

29. dos Santos, P. L.; Ward, J. S.; Congrave, D. G.; Batsanov, A. S.; Eng, J.; Stacey, J. E.; Penfold, T. J.; Monkman, A. P.; Bryce, M. R. Adv. Sci. 2018, 5, 1700989. doi:10.1002/advs.201700989

30. Adamo, C.; Barone, V. J. Chem. Phys. 1999, 110, 6158-6170. doi:10.1063/1.478522

31. Pople, J. A.; Binkley, J. S.; Seeger, R. Int. J. Quantum Chem. 1976, 10 (Suppl. 10), 1-19. doi:10.1002/qua.560100802

32. Grimme, S. Chem. Phys. Lett. 1996, 259, 128-137. doi:10.1016/0009-2614(96)00722-1

33. Hirata, S.; Head-Gordon, M. Chem. Phys. Lett. 1999, 314, 291-299. doi:10.1016/s0009-2614(99)01149-5

34. Jesser, A.; Rohrmüller, M.; Schmidt, W. G.; Herres-Pawlis, S. J. Comput. Chem. 2014, 35, 1-17. doi:10.1002/jcc.23449

35. Hansch, C.; Leo, A.; Taft, R. W. Chem. Rev. 1991, 91, 165-195. doi:10.1021/cr00002a004

36. Gao, X.; Bai, S.; Fazzi, D.; Niehaus, T.; Barbatti, M.; Thiel, W. J. Chem. Theory Comput. 2017, 13, 515-524. doi:10.1021/acs.jctc.6b00915

37. Cai, M.; Auffray, M.; Zhang, D.; Zhang, Y.; Nagata, R.; Lin, Z.; Tang, X. Chan, C.-Y.; Lee, Y.-T.; Huang, T.; Song, X.; Tsuchiya, Y.; Adachi, C.; Duan, L. Chem. Eng. J. 2021, 127591. doi:10.1016/j.cej.2020.127591

\section{License and Terms}

This is an Open Access article under the terms of the Creative Commons Attribution License (https://creativecommons.org/licenses/by/4.0). Please note that the reuse, redistribution and reproduction in particular requires that the author(s) and source are credited and that individual graphics may be subject to special legal provisions.

The license is subject to the Beilstein Journal of Organic Chemistry terms and conditions:

(https://www.beilstein-journals.org/bjoc/terms)

The definitive version of this article is the electronic one which can be found at: https://doi.org/10.3762/bjoc.17.21 